\title{
Elevated Hoxb5b expands vagal neural crest pool and blocks enteric neuronal development in zebrafish
}

Aubrey G. Adam Howard IV ${ }^{1}$, Aaron C. Nguyen ${ }^{1}$, Joshua Tworig ${ }^{2}$, Priya Ravisankar ${ }^{3,4}$, Eileen W. Singleton ${ }^{1}$, Can Li ${ }^{2}$, Grayson Kotzur ${ }^{1}$, Joshua S. Waxman ${ }^{3}$, and Rosa. A. Uribe*1

${ }^{1}$ BioSciences Department, Rice University, Houston, TX 77005, United States.

${ }^{2}$ Division of Biology and Biological Engineering, California Institute of Technology, Pasadena, CA 91125, United States

${ }^{3}$ Molecular Cardiovascular Biology Division, Cincinnati Children's Hospital Medical Center and Department of Pediatrics, University of Cincinnati College of Medicine, Cincinnati, OH 45229, United States.

${ }^{4}$ Allen Institute of Immunology, Seattle, WA 98107, United States

*corresponding author, email address: rosa.uribe@rice.edu

Key words: neural crest, hox, zebrafish, enteric neuron, differentiation 


\begin{abstract}
Neural crest cells (NCCs) are a migratory, transient, and multipotent stem cell population essential to vertebrate embryonic development, contributing to numerous cell lineages in the adult organism. While great strides have been made in elucidating molecular and cellular events that drive NCC specification, comprehensive knowledge of the genetic factors that orchestrate NCC developmental programs is still far from complete. We discovered that elevated Hoxb5b levels promoted an expansion of zebrafish NCCs, which persisted throughout multiple stages of development. Correspondingly, elevated Hoxb5b also specifically expanded expression domains of the vagal NCC markers foxd3 and phox $2 b b$. Increases in NCCs were most apparent after pulsed ectopic Hoxb5b expression at early developmental stages, rather than later during differentiation stages, as determined using a novel transgenic zebrafish line. The increase in vagal NCCs early in development led to supernumerary Phox $2 \mathrm{~b}^{+}$enteric neural progenitors, while leaving many other NCC-derived tissues without an overt phenotype. Surprisingly, these NCCderived enteric progenitors failed to expand properly into sufficient quantities of enterically fated neurons and stalled in the gut tissue. These results suggest that while Hoxb5b participates in vagal NCC development as a driver of progenitor expansion, the supernumerary, ectopically localized NCC fail to initiate expansion programs in timely fashion in the gut. All together, these data point to a model in which Hoxb5b regulates NCCs both in a tissue specific and temporally restricted manner.
\end{abstract}




\section{$\underline{\text { Introduction }}$}

As an embryonic stem cell population in vertebrates, neural crest cells (NCCs) are renowned for their remarkable migratory capacity, as well as their multipotency. Born from the dorsal neural tube, NCCs migrate along stereotypic routes throughout the early embryo and give rise to a wide range of diverse tissue lineages, such as craniofacial skeleton, portions of the peripheral nervous system, and pigment cells (Rocha et al., 2020). NCCs exhibit regional potential along the anteroposterior (AP) neuraxis such that they may be divided into four general populations: cranial, vagal, trunk, and sacral (Le Douarin, 1982; Le Douarin and Kalcheim, 1999). Each of these populations give rise to numerous discrete lineages, for example, cranial NCC largely give rise to cell lineages in the head. Particularly of interest are vagal NCCs, which contribute to several tissues, such as the cardiac outflow tract and nearly all of the enteric nervous system (ENS) (Tang et al., 2021) within the gut, and have been less well characterized than other populations (Hutchins et al., 2018). While the driving genetic factors which regulate the general pattern of NCC developmental trajectories have been well described (Martik and Bronner, 2017; Simoes-Costa and Bronner, 2016), we still have an incomplete understanding of what genes function in context of vagal NCC development and their subsequent differentiation.

One factor that has been implicated in vagal NCC development is Hoxb5. In mice, dominant negative abrogation of embryonic Hoxb5 activity alters vagal and trunk NCC development, with reduced NCCs observed en route to and along gut tissue, as well as decreased numbers of melanoblasts throughout the body (Kam and Lui, 2015; Lui et al., 2008). Additionally, Hoxb5 may regulate expression of key genes active in NCC development, notably Foxd3 (Kam et al., 2014a) and Phox2b (Kam and Lui, 2015). The orthologous gene in zebrafish, hoxb5b, which is the primary ortholog in teleost fishes (Jarinova et al., 2008), was detected in differentiating NCC lineages at both 48 and 68 hours post fertilization (hpf) (Howard et al., 2021), suggesting it may also play a role during zebrafish NCC development. While characterization of zebrafish hoxb5b 
mRNA expression in situ has been pervasively characterized in several early embryonic contexts, such as the mesoderm and limb buds (Hortopan and Baraban, 2011; Jarinova et al., 2008; Kudoh et al., 2001; van der Velden et al., 2012; Waxman et al., 2008), the functional role of hoxb5b with respect to NCC development had not yet been examined.

Here, we postulated that hoxb5b functions as a potential driver of vagal NCC development. We provide evidence that overexpression of hoxb5b is sufficient to grossly expand NCC populations throughout the embryo, in addition to ectopic expansion of vagal domains marked by foxd3 and phox $2 b b$. The functional window of Hoxb5b activity was also restricted to a narrow developmental span, early during embryogenesis, rather than during NCC differentiation stages. The early expansion of NCC, however, did not lead to corresponding pan increases in NCC-derived tissues. Rather, elevated Hoxb5b activity expanded enteric neural progenitor cell pools along the gut, yet suppressed their subsequent expansion as they differentiated into enteric neurons, leading to overall fewer neurons along the gut. These data cumulatively support a model in which hoxb5b is a potent regulator of NCC expansion and cell number in zebrafish.

\section{$\underline{\text { Results }}$}

\section{hoxb5b is expressed in post-otic vagal NCCs during zebrafish development}

We examined hoxb5b expression in zebrafish embryos (Figure 1A) using whole mount in situ hybridization (ISH). At $32 \mathrm{hpf}$, hoxb5b was expressed bilaterally immediately posterior to the otic vesicle (post-otic), along the foregut, in the hindbrain, and anterior spinal cord (Figure 1B), as previously described (Jarinova et al., 2008). hoxb5b persisted in all three domains at $50 \mathrm{hpf}$ (Figure 1C), though the post-otic domains (POD) were slightly restricted and the hindbrain/spinal cord expression gained a more defined posterior boundary. By $77 \mathrm{hpf}$, hoxb5b expression remained largely in the hindbrain and foregut, with diminished yet persistent expression in the 
POD (Figure 1D). Together, these ISH data reveal changing post-otic spatiotemporal expression patterns of hoxb5b during the first four days of development.

We next examined the relationship of hoxb5b expression to the vagal NCC population during NCC specification and migration phases. NCCs were assayed by using the zebrafish panNCC marker crestin (Luo et al., 2001), in combination with hoxb5b, via hybridization chain reaction (HCR) (Choi et al., 2010, 2016, 2018). At 17 hpf, crestin ${ }^{+} / h o x b 5 b^{+}$cells were present dorsally (Figure 1E-G, white arrowheads), as well as ventral-laterally, along a post-otic stripe (Figure 1E-G, yellow arrowhead), revealing that hoxb5b is expressed within the POD vagal NCC population. crestin ${ }^{+} / h o x b 5 b^{+}$regions persisted by $24 \mathrm{hpf}$ dorsally, in posterior hindbrain/anterior spinal cord axial levels (Figure 1H-J, white arrowheads). Concurrently at this stage, hoxb5b expression within the stripe became internalized within the POD vagal NCC population, marking the central cells of this region and highlighting several NCCs which expressed hoxb5b (Figure 1H-J, yellow arrowhead). Between 30-36 hpf, the stripe co-positive hoxb5 $\mathrm{b}^{+} / \mathrm{crestin}^{+}$stripe of POD vagal NCC persisted (Figure 1K-P, yellow arrowheads), and $c r e s t i n^{+} / h o x b 5 b^{+}$cells were still observed along the dorsal neural tube. These data are consistent with our prior findings in which hoxb5b mRNA was present in posterior neural crest at $48 \mathrm{hpf}$ and $68-70 \mathrm{hpf}$ (Howard et al., 2021). Collectively, the ISH and HCR data indicate that hoxb5b mRNA expression is coincident with a subset of vagal NCCs, persisting throughout the developmental window spanning NCC specification and well into their migration phase, highlighting hoxb5b's potential role as a driver of vagal NCC development.

Elevated Hoxb5b activity globally promotes expanded localization and increased number of NCC in vivo

While other work has focused exclusively on the loss of function of Hoxb5 related genes (Dalgin and Prince, 2021; Lui et al., 2008), we have sought to understand the gain of function role 
of hoxb5b in the context of NCC development. To examine the possible role of hoxb5b in NCC, we employed a hyperactive vp16-hoxb5b fusion construct (Waxman and Yelon, 2009; Waxman et al., 2008). Injection of vp16-hoxb5b mRNA resulted in expansion of NCC, when compared to control embryos at $32 \mathrm{hpf}$, as assayed with an ISH probe against crestin (Figure $\mathbf{2 A}, \mathbf{B}$ ). The expansion in NCC territory was prominent in the pre-otic region (Figure 2B; white arrowheads), the POD (Figure 2B; yellow arrowheads) and along the spinal cord-level of the trunk (Figure 2B; red arrowheads). Strikingly, post-otic expansion persisted along the dorsal-ventral and anterior-posterior axes well through NCC migration phases at 50 hpf (Figure 2C,D; arrowheads). Furthermore, quantification of the area occupied by POD NCCs corroborated the observed expansion of NCC localization (Figure 2E).

To better understand the spatiotemporal distribution of the increased NCC following vp16hoxb5b expression, we utilized confocal microscopy to image -7.2sox10:mRFP transgenic embryos (referred to here as sox10:mRFP) (Kucenas et al., 2008), where NCC are labeled using a membrane bound RFP. Congruent with our prior findings (Figure 2A, B), at 24 and $33 \mathrm{hpf}$, confocal projections revealed vp16-hoxb5b expressing embryos exhibited broadened POD vagal NCC domains along the anterior-posterior and medio-lateral axes (Figure 2G, G', I, I'; arrowheads), when compared to control embryos (Figure 2F, F', H, H'; arrowheads). This expansion was coupled with an increase in the number of POD NCC. By 43 hpf, vp16-hoxb5b expressing embryos displayed a striking expansion of the POD NCC, as well as a disruption of the overall architecture of the domain, which extended further laterally from the dorsal midline (Figure 2K'), than in control (Figure 2J'). Moreover, vp16-hoxb5b promoted ectopic accumulation of cells along the dorsal midline of the spinal cord (Figure 2K"), which were not observed in control embryos (Figure 2J'). Considered together, these data (Figure 2) indicate that elevated Hoxb5b activity alters NCC patterning along the embryo as well as expanding their cell number. 


\section{Elevated Hoxb5b activity is sufficient to expand vagal NCC marker expression}

That vp16-hoxb5b expressing embryos contained an overabundance of NCC, and that the overproduced NCC were prominently enriched in the vagal axial levels suggests that excess Hoxb5b activity influences vagal NCC development in zebrafish. To examine if vagal NCC specification was altered following excess Hoxb5b activity, we assayed the expression of canonical marker genes of the vagal NCC, foxd3 (Lister et al., 2006) and phox2bb (Elworthy et al., 2005). At $32 \mathrm{hpf}$, foxd3 expression serves as an indicator of multipotent NCC while phox $2 b b$ indicates NCCs which are now specified to an autonomic neural lineage, particularly the ENS (Pattyn et al., 1999; Uribe and Bronner, 2015). vp16-hoxb5b expression was sufficient to widen foxd3 expression domains at $32 \mathrm{hpf}$, principally along the anterior-posterior and mediolateral directions in the vagal region, when compared to control expression patterns (Figure 3A,B; black bars). We found that $v p 16-h o x b 5 b$ expression expanded the POD foxd $3^{+}$area, leading to a 1.95 fold increase in the mean domain size compared to controls (Figure 3E). Additionally, phox2bb was also greatly expanded in response to increased Hoxb5b activity along the hindbrain (Figure 3C,D; black bars), with expansion uniformly in both the anterior-posterior and mediolateral axis, similar to the expansion of the foxd3. Measuring the hindbrain phox $2 b b^{+}$domain, we observed a $43 \%$ increase in the phox $2 b b$ expressed area throughout the hindbrain following elevated Hoxb5b (Figure 3F). Lastly, POD phox2bb expression was dramatically altered by elevated Hoxb5b

(Figure 3C,D; white arrow heads), with a 2.14 times mean increase in domain size compared to wild-type controls (Figure 3G). In all, these data indicate that elevated Hoxb5b activity drastically expands vagal NCC marker expression along the embryo.

In support of the specific expansion of POD localized phox $2 b b$ expression, we also observed a corresponding increase in the number of Phox $2 \mathrm{~b}^{+}$cells, via whole mount fluorescent Immunohistochemistry (IHC), using an antibody against Phox2b (Figure 3-Supplement 1A-C; 
Figure 3). At 32 hpf, Phox $2 b^{+}$cells were observed in the POD, with 16 cells on average (Figure 3L; arrowhead, Figure 3K). Overexpression of Hoxb5b stimulated a dramatic expansion of POD Phox $2 \mathrm{~b}^{+}$cells (Figure 3l,J; arrowheads). The increase in POD Phox $2 \mathrm{~b}^{+}$cells was also concordant with an increase in vp16-hoxb5b dosage, with 77 and 107 mean POD Phox $2 b^{+}$cells per animal detected following injection with either $15 \mathrm{pg}$ or $30 \mathrm{pg}$ of mRNA, respectively (Figure 3K). The quantifiable increase in POD Phox $2 \mathrm{~b}^{+}$cells is confirmatory of our prior qualitative observations regarding increased cell number (Figure 2) and positions Hoxb5b as a potent driver of NCC number and localization.

\section{Hoxb5b overexpression increases NCC production during early NCC development}

While we observed supernumerary NCCs ectopically localized, and expanded expression of vagal NCC specification factors following global expression of vp16-hoxb5b mRNA, exactly when during NCC development Hoxb5b may exert its influence was still unclear. To investigate the potential temporal role(s) of Hoxb5b during NCC development, we created and utilized a novel transgenic line, $\operatorname{Tg}\left(\right.$ hsp70l:EGFP-hoxb5b;cryaa:dsRed) ${ }^{\mathrm{ci1014}}$ (hereafter referred to as hsp70I:GFPhoxb5b), which enables pan ectopic expression of a GFP-Hoxb5b protein fusion under the thermally inducible hsp70I promoter (Kwan et al., 2007) (Figure 4A). The transgene can then be activated by rapidly transferring embryos to warm $37^{\circ} \mathrm{C}$ culture conditions, which drives strong global expression of the EGFP-Hoxb5b fusion protein throughout the embryonic tissues (Figure 4 - Supplement 1A). EGFP-Hoxb5b demonstrated robust and distinctive nuclear localization, which was still detectable over 24 hours after embryos were returned to $28^{\circ} \mathrm{C}$ (Figure 4Supplement B-C).

Two early phases in NCC development were tested, with heat shocks conducted starting either at $14 \mathrm{hpf}$, during NCC specification, or $22 \mathrm{hpf}$, early during the migratory span of posterior NCCs (Figure 4B). After heat shock at $14 \mathrm{hpf}$, whole mount ISH at $24 \mathrm{hpf}$ showed enlargement 
of crestin ${ }^{+}$NCC domains in GFP-Hoxb5b+ embryos, over the GFP-Hoxb5b- sibling controls (Figure 4C-D), particularly prevalent in the POD NCC (Figure 4D; yellow arrowheads). This increase in area was also accompanied by a qualitative increase in the number of crestin $^{+}$cells along the posterior dorsal length of the embryo, similar to the phenotype observed in the previous Hoxb5b mRNA overexpression assays (Figure 2A-E). Quantified area of crestin ${ }^{+}$PODs confirmed the expansion of vagal NCCs (Figure 4I). Additionally, subtle expansion of cranial NCCs (Figure 4C-D, white arrowheads) and pre-otic NCCs (Figure 4C-D, red arrowheads) was also observed, though far less striking than that of the vagal population at this stage. These data indicate that NCC localization during early specification phase of NCC development is receptive to Hoxb5b activity.

GFP-Hoxb5b induction at $22 \mathrm{hpf}$ also increased crestin staining by $26 \mathrm{hpf}$ throughout the POD (Figure 4E-H, yellow arrowheads), which is especially prominent in the NCCs most proximal to the otic vesicles (Figure G-H, red arrowheads). As in the heat shock at $14 \mathrm{hpf}$, increased NCC localization was also observed in GFP-Hoxb5b+ embryos across the cranial NCC populations (Figure 4E-H; white arrowheads). Interestingly, while this later heat shock did not significantly expand measurable vagal NCC area (Figure 4J), it did increase their abundance (Figure E-H). Nonetheless, this subtle difference in only a few hours of development indicates a critical period during early NCC development in which Hoxb5b is sufficient to promote NCC localization in the developing vertebrate body.

\section{Increased Hoxb5b alters specific vagal NCC-derived tissues}

Due to the multipotent nature of NCC, it is possible a wide diversity of tissues can be affected by even a small perturbation in NCC development. Because we observed an overproduction of NCC following increases in Hoxb5b activity, we wondered if downstream NCC derivatives were also affected. Therefore, we first investigated the effect of vp16-hoxb5b 
expression on vagal and trunk NCC-derived cell types; including, pigment cells (melanophores and iridophores) and neuronal derivatives. Embryos expressing vp16-hoxb5b were able to produce pigment cells without appreciable differences (Figure 5 - Supplement 1 A-D). Both dorsal root ganglia (DRG) and Superior Cervical Ganglion (SCG) are derived from the vagal/trunk NCC pool (Durbec et al., 1996). Neurons comprising the DRG and SCG were largely normal following vp16-hoxb5b injection (Figure 5 - Supplement 1 E-H).

We next assayed the NCC-derived cell population along the gut length (Figure 5A), enteric neural progenitors, which typically migrate to the midgut level by $2 \mathrm{dpf}$ and will have colonized the hindgut by $3 \mathrm{dpf}$, giving rise to neurons of the enteric nervous system (Ganz, 2018). We found that by $50 \mathrm{hpf}$, Phox $2 \mathrm{~b}^{+}$enteric neural progenitors significantly increased after vp16hoxb5b expression (Figure 5C-D), compared to the controls (Figure 5B). Counting Phox $2 \mathrm{~b}^{+}$cells in the POD and along the gut tract (Figure 5B-D; white dashes), revealed the number of cells trended with increasing amount of $v p 16-h o x b 5 b$ mRNA injected (Figure 5E), consistent with the phenotype at $32 \mathrm{hpf}(\mathbf{F i g u r e} \mathbf{3 H}-\mathbf{J})$. The supernumerary enteric neural progenitors were observed together with their accumulation along the foregut (Figure 5B-D; yellow arrowheads) and in the POD (Figure 5F), though an increase in the number of cells was also observed at the end of the enteric migration chain along the midgut (Figure 5 - Supplement 1I; Figure 5C,D; white arrowheads). The increase in cells was uniform across the gut tract, with no change in the fraction of Phox $2 \mathrm{~b}^{+}$cells found in the POD or gut mesenchyme after Hoxb5b perturbation (Figure 5 Supplement 1J). These findings indicate that elevated Hoxb5b elicits a global increase in enteric neural progenitor number through the first two days of development.

To determine if the supernumerary enteric cells were capable of differentiating into neurons later in development, we utilized -8.3phox2bb:kaede transgenic embryos which label enteric progenitors during their early neuronal differentiation (Harrison et al., 2014). Surprisingly, despite the increase in enteric progenitors at $50 \mathrm{hpf}$, enteric neurons by the $3 \mathrm{dpf}$ were 
dramatically decreased in vp16-hoxb5b expressing embryos compared to controls. Kaede ${ }^{+}$cells successfully colonized the gut length by 3 dpf in control embryos (Figure 5G; white arrowhead),

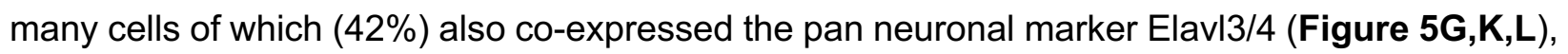
signaling the onset of neuron differentiation. In contrast, vp16-hoxb5b expressing embryos at both doses displayed a drastic loss of $\mathrm{Kaede}^{+}$and Elavl3/4+ enteric cells (Figure $\mathbf{5} \mathbf{J}, \mathbf{K}$ ), with the remaining Kaede ${ }^{+}$cells failing to localize past the level of the midgut (Figure $\mathbf{5 H}$,l; white arrowheads). The fraction of Elavl $3 / 4^{+} / \mathrm{Kaede}^{+}$cells in both $v p 16$-hoxb5b expressing conditions were reduced, at .31 and .28 respectively, when compared to control at .42 (Figure 5L). While not reaching significance, when these data are taken together with the significant reduction in total enteric cell numbers along the gut (Figure $\mathbf{5} \mathbf{J}, \mathbf{K}$ ), they likely indicate that general enteric progenitor pool depletion along the gut affects subsequent proper numbers of enteric neurons, following elevated Hoxb5b expression. Overall, these results suggest that while supernumerary enteric neural progenitors are present at and before $2 \mathrm{dpf}$ after elevated Hoxb5b, they largely depleted by the $3 \mathrm{dpf}$.

\section{Hoxb5b influences enteric patterning during early developmental stages}

In order to ascertain the timing during which excess Hoxb5b activity affects enteric nervous system development, we again leveraged the hsp70l:GFP-hoxb5b fish line. Embryos were heat shocked during NCC specification (14 hpf), migration (21 hpf), or differentiation (48 hpf), and all were fixed at $3 \mathrm{dpf}$, as schematized in Figure 6A. Embryos were assessed for enteric neuron abundance and localization via wholemount IHC, where Elavl $3 / 4^{+}$cells were counted along the gut tract (same region as in Figure 5A, box). When heat shocked at 14 or $21 \mathrm{hpf}$, GFP. Hoxb5 $b^{+}$embryos formed significantly fewer Elavl3/4 $/ 4^{+}$cells, when compared to their GFP-Hoxb5bsibling heat shock controls (Figure 6B-E, H). After heat shock at $48 \mathrm{hpf}$, GFP-Hoxb5b embryos did not significantly vary in number of Elavl3/4+ cells (Figure $6 \mathrm{~F}-\mathrm{H}$ ). The distribution of Elavl3/4 
cells was weighted more heavily toward the midgut, though cells could be detected along the entire length of the gut in GFP-Hoxb5 $b^{+}$embryos. This genetically encoded elevation of Hoxb5b activity during early NCC developmental phases corroborated the abrogation in Elavl $3 / 4^{+}$cells resulting from $v p 16-h o x b 5 b$ mRNA injection. Overall, these data indicate that the ability of GFPHoxb5b to affect enteric neuron number is limited to early stages of NCC development, but not thereafter.

\section{Excess Hoxb5b leads to stalled enteric nervous system development}

We had thus far discovered that Hoxb5b was sufficient to strongly increase NCCs at 30 and $50 \mathrm{hpf}$, but suppressed the number of enteric neural progenitor cells by $3 \mathrm{dpf}$. The loss in cells could easily be explained by an acute wave of cell death during enteric neural progenitor migration. We tested this hypothesis with whole mount IHC probing for activated Caspase-3, a marker for apoptotic cells (Sorrells et al., 2013), as well as Phox2b to label enteric neural progenitors. In addition, we also conducted these experiments in the $\mathrm{Tg}(-4.9$ sox 10 :EGFP) embryos (hereafter referred to as sox10:GFP) (Carney et al., 2006), which marks migratory NCCs with cytoplasmic GFP, and relying on residual GFP signal post fixation to label the recently sox $10^{+}$ enteric neural progenitor cells, as we have previously (Howard et al., 2021). Notably, Caspase- $3^{+}$ cells were rare in all controls tissues examined from 33 to 66 hpf (Figure 7 - Supplement 1A,C,E,G). While small patches of apoptotic cells can be found proximal to the POD at $33 \mathrm{hpf}$ and $55 \mathrm{hpf}$ (Figure 7 - Supplement 1B,D), there was not a detectable onset of cell death between 55 and 66 hpf along the entire vagal and gut region (Figure 7 - Supplement 1F,H) to support the loss of enteric neural progenitors through apoptosis following Hoxb5b overexpression.

We next examined the progenitor state of enteric cells at $63 \mathrm{hpf}$, a window of development prior to the $3 \mathrm{dpf}$ cut off, but after the 50 hpf NCC expansion noted previously. To this end, we asked if sox10:GFP+ and/or Phox $2 \mathrm{~b}^{+}$cell numbers were reduced along the gut at $63 \mathrm{hpf}$. 
Intriguingly, vp16-hoxb5b did not lead to a significant change in the total number of $\mathrm{GFP}^{+}$cells along the gut tube at $63 \mathrm{hpf}$ (Figure 7A-C). Similarly, there was no change in the number of Phox $2 \mathrm{~b}^{+}$cells, compared with control embryos (Figure 7C). This was in contrast to our earlier observation that enteric Phox2B $\mathrm{B}^{+}$cells were increased at 50 hpf (Figure 5). Furthermore, the fraction of sox10:GFP ${ }^{+}$cells expressing Phox2b was roundly unchanged (Figure 7D). Therefore, we found that by $63 \mathrm{hpf}$ the enteric progenitors exhibited enteric differentiation capacity, despite their decreased abundance in the presence of excess Hoxb5b.

That we observed increased Phox $2 \mathrm{~b}^{+}$cells at 32 and $50 \mathrm{hpf}$, yet saw a dampening of their numbers by $63 \mathrm{hpf}$, this suggested that the kinetics of enteric progenitor expansion may have been adversely affected following elevated Hoxb5b. Plotting the total number of Phox $2 \mathrm{~b}^{+}$cells counted from each developmental stage assayed throughout this study (Figure 7E) revealed a steady increase in control Phox $2 \mathrm{~b}^{+}$cells with developmental age, whereas Hoxb5b overexpressing animals present a stalled curve at $63 \mathrm{hpf}$. As we previously have shown that the enteric cells are not cleared by apoptosis during the $63-80 \mathrm{hpf}$ transition, these results indicated that Hoxb5b activity modulates enterically-fated NCC capacity to expand as a population along the gut. The Hoxb5b-dependent precocious expansion of NCC leads to a fixed number available progenitors which are then unable to expand in sufficient numbers to lead to proper ENS formation. These findings position Hoxb5b as a fine-scale regulator of enteric NCC number.

\section{Discussion}

We discovered that throughout the course of NCC specification and migratory phases, hoxb5b is expressed within subsets of vagal NCCs along the post-otic/posterior zebrafish embryo. Enhancement of Hoxb5b activity was sufficient to dramatically expand NCC localization patterns, as well as their number, along the embryo. The expansion of NCCs was also accompanied by domain expansions in vagal NCC marker genes phox $2 b b$ and foxd3. Temporally-restricted pulses 
of ectopic Hoxb5b during early vagal NCC developmental phases was sufficient to swiftly expand vagal NCC populations, which also persisted well into the second day in development. While many vagal NCC derivatives were unaltered by $3 \mathrm{dpf}$, NCC derivatives along the enteric neural trajectory were dramatically impacted. While we observed an increase in enteric neural progenitors along the developing gut tube at $50 \mathrm{hpf}$, they failed to expand and colonize the gut efficiently, resulting in a marked decrease in the number of enteric neurons. The decrease in the number of enteric neural progenitors following Hoxb5b induction appears to be due to a Hoxb5bdependent modulation of the colonization capacity of enteric neural progenitors. Cumulatively these data position Hoxb5b as a potent regulator of NCC patterning and number during early embryonic development (Figure 7F).

The potential involvement of Hoxb5b in zebrafish NCC development has been suggested by previous expression analyses, with discrete expression along the dorsolateral neural tube and in the post-otic domain, posterior to rhombomere 8 (Barsh et al., 2017; Jarinova et al., 2008; Kudoh et al., 2001; Waxman et al., 2008). Additional expression domains are found within the lateral plate mesoderm and foregut by $24 \mathrm{hpf}$ (Dalgin and Prince, 2021). As identified in a single cell atlas of posterior zebrafish NCC lineages at 48-50 and 68-70 hpf, hoxb5b was among the most pervasively expressed transcripts encoding for a Hox transcription factor in both the NCC and in neural fated lineages (Howard et al., 2021). Extending this prior work, our HCRs show for the first time at high resolution the persistent expression of hoxb5b in zebrafish posterior (postotic) NCC through the early course of their development.

In our zebrafish model, despite the regional potential exhibited by NCCs (Rocha et al., 2020), elevated Hoxb5b uniformly expanded both cranial, vagal, and trunk NCC progenitors, though more robustly among the posterior NCC populations. Whether the Hoxb5b-dependent increase in NCCs is driven by increased NCC specification from the neural tube or through upregulation of NCC proliferation remains unresolved and was beyond the current scope of this 
study. Regardless of the underlying mechanism, these findings clearly indicate that Hoxb5b participates in NCC development from an early position in the NCC gene regulatory network (Martik and Bronner, 2017; Simoes-Costa and Bronner, 2016). Further, the rapid sensitivity of vagal NCC to temporally restricted pulses of elevated Hoxb5b suggests competency of these cells to abruptly respond to Hox activity early in their development. Indeed, early NCCs appear sensitive not only to Hox mediated activity but also the amount of Hoxb5b present. In our injection experiments, POD NCCs increased coordinately with amount of vp16-hoxb5b mRNA delivered. As such, the number of cells fated in select NCC lineages, such as the enteric NCCs, appear to be influenced not only by the activation of Hoxb5b-dependent activity, but also in part through the levels of Hoxb5b expression. From data derived across multiple animal models, Hoxb5b and its orthologues are known to be under control of several classical morphogenic signals, including WNTs (Lengerke et al., 2008), NOTCH (Hortopan and Baraban, 2011), and Retinoic Acid (Waxman et al., 2008), which enables fine spatiotemporal tuning of the levels of Hox expression. Summarily, our data thus illuminate a model in which Hoxb5b serves a potent regulator of posterior NCC identity and cell number, dependent on additional unspecified cofactors as well as its expression level.

Our findings regarding Hoxb5b in zebrafish NCC is complementary to and extends the developmental understanding of mammalian Hoxb5. For example, dominant negative suppression of Hoxb5 activity in NCC lineages led to a depletion of several NCC-derived cell populations including DRGs, pigment cells, as well as enteric neural progenitors (Kam et al., 2014b; Lui et al., 2008). Complementing these prior loss of function studies, our gain of function data indicates that elevated Hoxb5b activity is sufficient to induce expansion of vagal NCC progenitors - that paradoxically also leads to severe ENS hypoganglionosis. While we did not observe corresponding changes in DRG and pigment populations in our experiments; early enteric progenitors were dramatically increased in response to Hoxb5b activity along the gut, prior to the onset of neurogenesis, yet failed to properly execute enteric neuronal differentiation. The 
insufficiency of ectopic Hoxb5b to expand the DRG and pigment lineages suggests a separate regulatory mechanism for Hoxb5b gain of function activity in enteric NCC. Indeed, the specificity of the effect elevated Hoxb5b on NCC populations; despite global elevated Hoxb5b activity in both the heat shock and mRNA injection assays, only ENS progenitor pool was roundly perturbed, indicating a particular receptivity of this population to Hoxb5b transcriptional regulation. One possible frame work to explain this phenomena is the presence of additional co-factors, such as other Hox transcription factors and their regulators, within the ENS linage which cooperate with Hoxb5b to facilitate this specificity. Intriguingly, overexpression of murine Hoxa4, another proximally expressed Hox transcription factor, is also endemic to the gut nervous network and is known to result in megacolon when over expressed, a phenotype indicative of enteric neural crest disruption (Tennyson et al., 1993; Wolgemuth et al., 1989). Reflecting on the emerging numerous descriptions of combinatorial "Hox Codes" which define NCC identity (Howard et al., 2021; Parker et al., 2019; Soldatov et al., 2019), the prospect of a shared sensitivity in enteric NCCs to Hoxb5b and Hoxa4 becomes a tantalizing speculation. When taken together with mammalian suppression of activity studies referenced above, our gain of function results suggest that the vertebrate embryo is exquisitely sensitive to perturbations in Hoxb5 activity, where either elevations or reductions in Hoxb5 lead to severe ENS defects.

Somewhat counterintuitively, the increase in POD NCCs following increased Hoxb5b activity did not correspondingly manifest a pan increase in vagal-derived NCC lineages. While many vagal-derived lineages exhibited no discernable phenotypic change, we actually observed a dramatic decrease in the number of enteric neurons in animals with elevated Hoxb5b activity. The shift in abundance of enterically fated cells was not the result of NCC-specific cell death or abrogated differentiation potential; indeed there was no change in fractions of enteric NCCs which had initiated differentiation programs following elevated Hoxb5b. Rather this tissue specific cell decrease appears to be the caused by a late-onset suppression of enteric neuroblasts expansion. These results suggest that Hoxb5b not only participates in regulating vagal NCC number over the 
influence of fate acquisition in this subset of NCC lineages. We find it tempting to speculate that perhaps the failure to perturb fate acquisition is at least in part mediated through functional redundancy of other Hox genes (Jarinova et al., 2008) as well as other factors, such as foxd3, which was grossly expanded following Hoxb5b ectopic activation. Foxd3 has previously been identified as a known transcriptional target (Kam et al., 2014a) and further modulates fate acquisition of several NCC lineages (Lukoseviciute et al., 2018). As the downstream mechanism remains to be elucidated, our findings here demonstrate for the first time that Hoxb5b is sufficient to grossly abrogate the expansion capacity of a very specific niche of NCCs, which suggests an exciting model for the role of additional Hox factors within the context of posterior NCCs. Collectively, our findings are in support of a model in which Hoxb5b plays an important role in NCC development, demonstrating the capacity to both expand vagal NCC localization and numbers. While additional questions still remain, these findings greatly inform our understanding of the role of posterior Hox genes in NCC development.

\section{Methods}

\section{Zebrafish Husbandry and transgenic lines}

Synchronously staged embryos for each experiment were collected via controlled breeding of adult zebrafish. After collection, embryos were maintained in standard E3 media at $28^{\circ} \mathrm{C}$ until 24 hours post fertilization (hpf), then transferred to $0.003 \%$ 1-phenyl 2-thiourea (PTU)/E3 solution (Karlsson et al., 2001), with the exception of larvae used to assay pigmentation, which were cultured in E3 media only. Transgenic embryos for the $\operatorname{Tg}(-4.9 \text { sox } 10: E G F P)^{\text {ba2Tg }}$ (Carney et al., 2006) and Tg(-7.2sox10:mRFP) ${ }^{\mathrm{vu} 234}$ (Kucenas et al., 2008) were generally sorted between 17-28 hpf for fluoresces while $\operatorname{Tg}(\text { hsp70l:EGFP-hoxb5b;acry:dsRed })^{\text {ci1014 }}$ and $\operatorname{Tg}(-$ 8.3phox2bb:kaede) (Harrison et al., 2014) embryos were sorted for transgenic expression between 60-78 hpf. Tissue was collected from embryos out of their chorions at the stage noted 
in each experiment as described in (Ibarra-García-Padilla et al., 2021). All work was performed under protocols approved by, and in accordance with, the Rice University Institutional Animal Care and Use Committee (IACUC).

\section{Generation of the $T g(h s p 70 I: E G F P-H o x b 5 b)$ transgenic line}

To generate EGFP-Hoxb5b, egfp was fused to the 5'-end of zebrafish hoxb5b with PCR. A sequence encoding a 7 amino acid linker was incorporated and the hoxb5b ATG was deleted to prevent alternative transcriptional initiation of hoxb5b downstream. To generate the hsp70l:EGFP-Hoxb5b transgene, standard Gateway methods were used (Kwan et al., 2007). The transgene includes a EGFP-Hoxb5b middle-entry vector and the reported p5E-hsp70I 5'Entry and p3E-polyA 3'-entry vectors (Kwan et al., 2007), which were incorporated into the pDestTol2-acry:dsRed vector (Mandal et al., 2013). Sanger sequencing was used to confirm the proper orientation of the constructs within the destination vector and the sequence of EGFP. hoxb5b. Transgenic embryos were created by co-injecting wild-type embryos at the one-cell stage with 25 pg hsp70l:EGFP-hoxb5b vector and 25 pg of Tol2 mRNA (Kawakami, 2004; Kawakami et al., 2004). Embryos were raised to adulthood and screened for the present of dsRed in the lens at $\sim 3$ days and the ability to induce robust EGFP expression following heat-shock (Figure 4 -

Supplement 1). Multiple founders for the $\operatorname{Tg}(h s p 70 l: E G F P \text {-hoxb5b;acry:dsRed })^{\text {ci1014 }}$ line were identified so the line that induced the most robust expression following heat-shock was retained. While some ectopic notochord expression was observed in non-heat shocked embryos they did not exhibit overt phenotypes and developed normally. For heat shock experiments, through routine outcrossing of transgenic animals to the wild type embryos of the $A B / T L$ backgrounds, GFP-hoxb5 $\mathrm{b}^{-/-}$siblings are produced with each subsequent breeding, which were heat shocked and processed in parallel.

\section{Preparation \& Injections of hoxb5b mRNA}


Capped vp16-hoxb5b mRNA was prepared off a Not1 linearized pCS2+ plasmid containing the vp16-hoxb5b coding sequence using the Sp6 mMessage Kit (Ambion), as first reported in (Waxman et al., 2008). The vp16-hoxb5b construct encodes for a hyperactive form of Hoxb5b and allowed for lower doses of mRNA to be delivered (Waxman and Yelon, 2009). Embryos were injected prior to the four-cell stage with either $15 \mathrm{pg}$ or $30 \mathrm{pg}$ of mRNA, which were cultured in parallel with uninjected siblings used for controls. Dead and grossly malformed embryos were removed from analysis.

\section{In Situ Hybridization}

In situ hybridizations were performed similarly to the protocol of Jowett and Lettice, 1994, which should be referenced for specific details. Briefly, antisense digoxigenin-labeled riboprobes were generated from previously characterized plasmids containing sequences for crestin (Luo et al., 2001), foxd3 (Hochgreb-Hagele and Bronner, 2013; Odenthal and Nüsslein-Volhard, 1998), phox2bb (Uribe and Bronner, 2015), and hoxb5b (Waxman et al., 2008). As per the protocol, whole mount embryos stored in methanol were rehydrated in PBST, permeabilized with Proteinase $\mathrm{K}$ digestion $(10 \mu \mathrm{g} / \mathrm{ml})$, and refixed in 4\% PFA. Embryos were incubated in probes overnight ( 16 hours) at $65^{\circ} \mathrm{C}$ and washed sequentially in graded SSCT buffers. Riboprobes solutions were recovered and stored at $-20^{\circ} \mathrm{C}$ for reuse, with multiple uses leading to minimal loss of signal. Probed embryos were blocked for $1-2$ hours at ambient temperature in $5 \%$ Goat sera in PBST before detection overnight ( 16 hours) at $4^{\circ} \mathrm{C}$ using an anti-Digoxigenin-Fab fragments conjugated to Alkaline Phosphatase enzymes (1:1000 dilution, Roche) in 5\% Goat Sera in PBST. Finally, riboprobes were visualized with NBT/BCIP solution $(3.5 \mu \mathrm{L}$ each of NBT, BCIP stock solutions, Roche). Probes were validated prior to use on wildtype embryos to calibrate staining duration, with patterns compared to those curated on ZFIN (Howe et al., 2013; Ruzicka et al., 2019).

\section{Whole mount Immunohistochemistry, HCR, and WICHCR}


Immunohistochemistry (IHC), Hybridization Chain Reaction (HCR), and Whole mount ImmunoCoupled Hybridization Chain Reaction (WICHCR) protocols all were conducted according to the methods published in Ibarra-García-Padilla et al., 2021. All IHC assays conducted in blocking 5\% Goat Sera in 1X PBST. Primary antibodies against the following proteins were used as follows: Phox2b (1:200, Santa Cruz, B-11), Kaede (1:500, MBL International, PM102M), Elavl3/4 (Same as $\mathrm{HuC} / \mathrm{D}, 1: 500$, Invitrogen Molecular Probes, A21271), Activated Caspase-3 (1:200, BD Biosciences, 559565). Incubation in primary antibody solutions were conducted overnight at $4^{\circ} \mathrm{C}$, except for assays with Phox2b or Caspase-3 antibodies which were allowed to incubate for two days at $4^{\circ} \mathrm{C}$ which provided optimal labeling. Corresponding secondary antibodies conjugated to spectrally distinct fluorophores were all used at 1:500 dilution, selected from the following depending on the experimental condition: Alexa Fluor 488 goat anti-rabbit IgG (ThermoFischer, A11008), Alexa Fluor 568 goat anti-rabbit IgG (ThermoFischer, A11011), Alexa Fluor 488 goat anti-mouse IgG1 (ThermoFischer, A21121), Alexa Fluor 594 goat anti-mouse lgG1 (ThermoFischer, A21125), Alexa Fluor 647 goat anti-mouse IgG1 (ThermoFischer, A21240), and Alexa Fluor 647 goat anti-mouse IgG2b (ThermoFischer, A21242). In the HCR \& WICHCR assays, commercially designed probes were secured from Molecular Instruments as follows: crestin (B3, AF195881.1), hoxb5b (B2, BC078285.1), phox2bb (B1, NM_001014818.1). Corresponding amplifiers were purchased from Molecular instruments and were used in experiments to include spectrally distinct fluorophores suitable for multiplexed imaging.

\section{Heat shock induction of the hsp70I:GFP-hoxb5b transgene}

Adult zebrafish maintained as an outcross and positive for dsRed expression as larvae in the lens (see above method on description of the line) were bred to produce synchronously staged embryos. At the stage designated to begin the heat shock, embryos were rapidly transferred to $37^{\circ} \mathrm{C}$ E3 and maintained at that temperature. After a 1-hour incubation, embryos were rapidly 
returned to $28^{\circ} \mathrm{C}$. In the 1-3 hours after heat shock GFP-Hoxb5b ${ }^{+}$embryos were sorted from GFPsiblings and cultured in parallel until the designated stage for tissue collection.

\section{Imaging, Quantification, and Image Visualization}

All embryos prior to imaging were cleared through graded washes of PBST/Glycerol to reach a final Glycerol content of $75 \%$. Fluorescent Z-stacked images of IHC processed embryos were captured using an Olympus FV3000 point scanning confocal microscope supported by Fluoview Acquisition Software (version FV31S-SW). Images were stitched in FIJI (Image J version 1.53e) using the Grid/Collection applet as part of the Stitching plugin (Rueden et al., 2017; Schindelin et al., 2012; Schneider et al., 2012). Digital image files were converted with ImarisFileConverter Software (Bitplane) to three dimensional rendered images compatible with IMARIS (V9.4, V9.7, Bitplane). Cells counts were conducted on volume images following an arithmetic background subtraction in IMARIS to ensure accurate counts, particularly when determining coincidence of labels. ISH processed embryos were imaged on a Nikon Eclipse Ni microscope equipped with a motorized stage. Z-stack images were acquired and extended depth of focus images were generated in the Nikon NIS-Elements BR software (v5.02.00). Areas of expression were measured in FIJI to include dark pixels in the post-otic or hindbrain domains. Quantifications were curated and analyzed in the Rstudio programming environment (v1.1.463). Images of pigmented embryos were captured similarly on the Nikon microscope with lateral illumination to distinguish iridophores, similar to (Petratou et al., 2021).

\section{In vivo Confocal Microscopy}

Embryos were sorted for RFP expression, anesthetized with $0.4 \%$ tricaine, and embedded in $1 \%$ low melting agarose in a $28.5^{\circ} \mathrm{C}$ chamber with a coverslip glass bottom. Care was taken to ensure embryo angled appropriately and proximal to the glass. Z-stack images were acquired approximately every half hour concurrently on the same Olympus FV3000 point scanning confocal 
microscope as above. Maximum intensity projections images were generated and exported from FIJI.

\section{Statistical Analysis}

An $\alpha$ of 0.05 was used as a cut off for all statistical tests. Normalcy of datasets was assessed by visual inspection of a density plot, a qqplot against a linear theoretical distribution, and ShapiroWilk test for Normalcy. Further, variance between each dataset was examined either with a Bartlett test for data which adhered to normalcy or with a Levene's test for non-normal data. Based on the normalcy and scedasticity conditions of the data, the appropriate statistical test was selected, as summarized in Table 1. All statistical analyses were carried out in the Rstudio (v1.1.463) programming environment, with key dependencies on the lawstat (v3.4) and stats (v3.6.3) packages. Plots were generated in Rstudio supported by the ggplot2 (v3.3.2) and ggsignif (v0.6.0) packages.

\section{Figure Legends}

Figure 1 - hoxb5b is expressed during early NCC development. (A) Schematized embryo illustrating approximate locations of major relevant anatomical features, namely the post-otic domain (POD), eye, yolk, Otic Vesicle (Ov), the Hindbrain (Hb), presumptive spinal cord (Sc), foregut mesenchyme (Fg), and Midgut mesenchyme (Mg). (B-D) In Situ Hybridization demonstrating hoxb5b expression in the posterior Hindbrain, Pod, and Fg during the second through third day of development. (E-P) Hybridization Chain Reaction probes against crestin and hoxb5b highlight their overlapping domains in the Pod (yellow arrowheads) and along the dorsal length (white arrowheads). Scale bars E,H: $50 \mu \mathrm{M}$.

Figure 2 - Elevated Hoxb5b activity globally increases both number and localization of neural crest cells. (A-D) In Situ Hybridization for NCC using a crestin probe at both $32 \mathrm{hpf}(\mathrm{A}, \mathrm{B})$ 
and 50 hpf $(C, D)$. crestin ${ }^{+}$domains for embryos injected with 15 pg of $v p 16-h o x b 5 b$ mRNA (B,D) were expanded in the post-otic (yellow arrowheads), cranial (white arrowheads), and spinal cord (red arrowheads) compared to uninjected embryos (A,C). (E) Quantification of expanded vagal crestin $^{+}$domains shows significant expansion at both $32 \mathrm{hpf}\left(p=0.75 \times 10^{-7}\right)$ and at $50 \mathrm{hpf}(p=$ 0.00114). (F-K) Maximum intensity projected stills taken from a confocal acquired time lapse of movies of sox10:mRFP embryos. Controls were compared to $30 \mathrm{pg} v p 16$-hoxb5b injected embryos, examined from $24 \mathrm{hpf}$ to $43 \mathrm{hpf}$ and serially imaged along the dorsal aspect of the vagal domain. mRFP ${ }^{+}$NCCs are grossly expanded in the vagal domain (G,G' arrowheads) over controls ( $F, F^{\prime}$, arrowheads). This expansion persists through the course of development, resulting in ectopically localized cells along the dorsal aspect of the embryo (K') and in the post-otic pool (K').

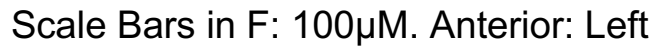

Figure 3 - Elevated Hoxb5b activity expands the expression domains of vagal markers foxd3 and phox $2 b b$ during the first day in development. (A-B) ISH against foxd3, a marker for multipotent NCCs at this stage, in 32 hpf. Embryos injected with 30 pg vp16-hoxb5b were compared to WT controls. (C-D) ISH against phox2bb, an autonomic NCC marker, in 32 hpf. Embryos injected with 30 pg vp16-hoxb5b were compared to WT controls. The POD is denoted with a white arrow head. (E-G) Quantified POD foxd3 expression (E, $p=0.00571$ ) or phox2bb expression $(F, p=0.138)$, as noted in representative images by black bars. The discrete post otic expression domain is quantified in $(\mathrm{G}, p=0.00563)$. Areas are normalized to control mean. $(\mathbf{H}-\mathbf{K})$ $\mathrm{IHC}$ detection of Phox $2 \mathrm{~b}^{+}$cells viewed along the lateral axis of $32 \mathrm{hpf}$ embryos reveal that WT controls already have a nascent population ( $\mathrm{H}$, white arrowheads). vp16-hoxb5b overexpression, at either $15 \mathrm{pg}(\mathrm{I})$ or $30 \mathrm{pg}(\mathrm{J})$ of mRNA injected, expands the Phox $2 \mathrm{~b}^{+}$vagal NCCs (white arrowheads). (K) Counted $\mathrm{Phoxb}^{+}$cells from 3 dimensional micrographs reveal increasing cells with the amount of vp16-hoxb5b mRNA (15 pg: $\left.p=3.03 \times 10^{-5} ; 30 \mathrm{pg}: \mathrm{p}=2.61 \times 10^{-5}\right)$. Scale bar $A, L: 100 \mu \mathrm{M}$ 
Figure 3-Supplement 1 - Phox2b antibody labeling is synonymous with mRNA \& transgenic labeling methods. (A) $3 \mathrm{dpf}-8.3 p h o x 2 b b: k a e d e$ larva co-labeled via WICHCR protocol (Ibarra-García-Padilla et al., 2021) showing transgene labeled cells (green), phox2bb mRNA (magenta), and Phox2b protein (cyan). (B) Inset images in the hindbrain exhibit robust coincidence of all three probes along the Hindbrain $(\mathrm{Hb})$, Pharyngeal $(\mathrm{Pa})$, and PODs (arrowheads). Kaede ${ }^{+}$cells which are negative for both mRNA and protein are detected at the dorsal most aspect of the motor neuron complex (star) as well as in anterior regions of the presumptive CNS. (C) Images highlighting the midgut axis reveals a perfect coincidence of all three enteric labels with very little background, demonstrating the efficacy of the Phox $2 b$ antibody as an enteric neural crest label. While nearly every cell is coincident, selected cells are annotated to aid in comparison (arrowheads). Scale bar A: $100 \mu \mathrm{m}$

Figure 4 - Temporally controlled overexpression of Hoxb5b during the first day in development are sufficient to expand the neural crest pool. (A) Schematized model of the hsp70l:gfp-hoxb5b;cryaa:dsRed genetic construct. (B) Illustration depicting specific periods of heat shock for embryo groups relative to classical hallmarks of NCC development. (C-D) ISH using a probe for crestin in hsp70l:GFP-hoxb5 $5 b^{+}$embryos heat shocked at $14 \mathrm{hpf}$ and fixed at 24 hpf, compared to GFP- sibling controls treated in parallel. Dramatic expansion of the POD can be seen (yellow arrowheads) in the Hoxb5b overexpressing embryos, while more subtle expansion is noted in the cranial NCC (white arrowheads) and pre-otic crest (red arrowheads). (E-H) Similar to (C-D) ISH with a crestin probe in hsp70l:gfp-hoxb5b and GFP- sibling controls heat shocked at $22 \mathrm{hpf}$ and fixed for ISH at $26 \mathrm{hpf}$, examining both crestin ${ }^{+}$domains both laterally (E-F) and dorsally (G-H). (I-J) Graphs depicting areas occupied by crestin staining in both GFP- control and Hoxb5b overexpressing embryos. Hoxb5b overexpression at $14 \mathrm{hpf}$ was sufficient to expand NCC localization and qualitatively NCC number (I, $p=0.0234)$. A later heat shock at $22 \mathrm{hpf}-$ fixation at $26 \mathrm{hpf}$, did not expand vagal NCC localization $(\mathrm{J}, p=0.1125)$, but did appear to increase crestin staining, indicative of an increase in NCC number. Scale bars C,E, G: $100 \mu \mathrm{M}$ 
Figure 4-Supplement 1 - Characterization of novel hsp70l:GFP-hoxb5b transgenic zebrafish line. (A) GFP-Hoxb5b+ overexpressing embryos are easily distinguishable from GFPsiblings one hour after heat shock. GFP- \& GFP ${ }^{+}$embryos are cultured and assayed under identical conditions to control for variations induced by growth at an elevated temperature. (B-C) GFP-hoxb5b construct is robustly localized to cell nuclei following heat shock and persists at least

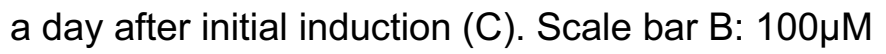

Figure 5 - Hoxb5b is sufficient to expand early enteric neural progenitors. (A) Schematized model of a zebrafish embryo highlighting the region of the gut tube, which is imaged in the following panels. (B-D) Whole mount IHC for Phox2b in 50 hpf control embryos (B) compared to embryos injected either with $15 \mathrm{pg}(\mathrm{C})$ or $30 \mathrm{pg}(\mathrm{D})$ of $v p 16$-hoxb5b mRNA. Yellow arrow heads indicated POD localized Phox $2 \mathrm{~b}^{+}$cells, white arrows designate terminal end of enteric NCC chain, which falls within the gut tract outlined with white dashes. (E-F) Quantified cell numbers reveal a coordinate increase in Phox $2 \mathrm{~b}^{+}$along the gut axis at $50 \mathrm{hpf}$ trending with increasing vp16-hoxb5b mRNA amounts (E, $\left.15 \mathrm{pg}: p=2.834 \times 10^{-5} ; 30 \mathrm{pg}: p=0.00318\right)$. Additionally, the number of Phox $2 \mathrm{~b}^{+}$cells restricted to the POD also increased in response to elevated Hoxb5b activity (F, 15 pg: $p=0.00328 ; 30$ pg: $p=0.00068)$ (G-I) Whole mount IHC on -8.3phox2bb:kaede embryos with antibodies against Elavl3/4 and Kaede, marking the enteric NCC lineage cells. (J-L) Quantification of the number of enteric neural progenitors $(\mathrm{J}, 15 \mathrm{pg}: p=0.00011 ; 30 \mathrm{pg}: p=4.09$ $\left.\times 10^{-5}\right)$ and differentiating enteric neurons $(\mathrm{K}, 15 \mathrm{pg}: p=0.001352 ; 30 \mathrm{pg}: p=0.0001042)$ at $3 \mathrm{dpf}$ show decreasing numbers of both cell populations. However, the total fraction of differentiating $\left(\mathrm{Hu}^{+}\right)$NCC-derived Kaede ${ }^{+}$cells unchanged following elevated Hoxb5b activity (L, 15 pg: $p=0$. 0.1282; 30 pg: $p=0.102)$. Scale Bar B,G: $100 \mu \mathrm{M}$

Figure 5-Supplement 1 - Vagal NCC derivatives following Hoxb5b overexpression are largely unaffected. (A-D) Investigation of distinct NCC derived pigment lineages, melanophores (red arrowheads) and iridophores (yellow arrowheads), in 5 dpf embryos overexpressing Hoxb5b 
compared to controls. (E-F) Both control embryos and Hoxb5b overexpressing embryos by $50 \mathrm{hpf}$ produced phenotypically wild type anterior dorsal root ganglia (DRG), as shown in whole mount immunolabeling with an antibody against Elavl3/4. (G-H) Position and development of the Superior Cervical Ganglion (SCG) occurs by the third day, as shown by immune labeling for Elavl3/4 (red arrowhead). (I) Quantifications from data reflect in Figure 5, showing the number of Phox $2 \mathrm{~b}^{+}$cells localized along the gut length, excluding the POD increases in response to vp16hoxb5b mRNA induction (I, 15 pg: $\left.p=9.92 \times 10^{-5} ; 30 \mathrm{pg}: p=0.000404\right)$. (J) The distribution of Phox $2 \mathrm{~b}^{+}$cells between the POD and the length of the gut was unchanged following elevated Hoxb5b activity (J, 15 pg in POD: $p=0.2515 ; 30$ pg in POD: $p=0.3673 ; 15$ pg in Gut: $p=0.2306$; 30 pg in Gut: $p=0.3496)$. Scale Bars E,F,G,H: $50 \mu \mathrm{m}$

Figure 6 - NCC sensitivity to increased Hoxb5b activity is restricted to earlier stages of development. (A) Schematized model of when heat shocks occurred relative to standard stages of NCC development in zebrafish. (B-H) Whole mount immunolabeled hsp70l:GFP-hoxb5b ${ }^{+}$ embryos and their GFP- sibling controls using an antibody against Elavl3/4. Embryos heat shocked either at $14 \mathrm{hpf}$ or $21 \mathrm{hpf}$ both exhibited fewer differentiating enteric neurons than controls. Numbers of enteric neurons are quantified in $(\mathrm{H}, \mathrm{HS} 14: p=0.000232 ; \mathrm{HS} 21: p=$ 0.001684; HS48: $p=0.5813)$. Scale Bar B: $100 \mu \mathrm{m}$

Figure 7 - Elevated Hoxb5b abrogates the expansion capacity of enteric NCC-derived neuronal lineage. (A-B) By 63 hpf, sox10:GFP embryos immunolabeled for Phox2b show cells which have partially migrated along the gut in both control and vp16-hoxb5b injected animals. Gut tract outlined with white dashes. (C) No changes were found in the number of GFP ${ }^{+} \mathrm{NCC}$ lineage or Phox $2 \mathrm{~b}^{+}$cells along the gut (Enteric GFP $: p=0.2619$; Enteric Phox $2 \mathrm{~b}^{+}: p=0.7896$ ). (D) Assessment of fraction of GFP ${ }^{+}$cells which are also positive for Phox $2 \mathrm{~b}^{+}$restricted to the gut axis, as a measure of NCC which have initiated their differentiation programs shows the fraction of Sox $10^{+}$lineage cells which have turned on Phox $2 \mathrm{~b}$ expression is unchanged following elevated 
Hoxb5b $(p=0.1253)$. (E) Summary of the number of Phox $2 \mathrm{~b}^{+}$cells for either WT control embryos or embryos injected with $15 \mathrm{pg} v p 16$-hoxb5b mRNA as a function of age. The trend shows while the number of Phox $2 b^{+}$cells initially is greater than WT, eventually the WT Phox $2 b^{+}$numbers continue to increase with the Phox $2 \mathrm{~b}^{+}$population in Hoxb5b elevated embryos remains flat. Error bars reflect \pm one standard deviation. (F) Graphical Model of the role of Hoxb5b in NCC development, such that early Hoxb5b expression grossly expands NCC numbers, while later in development Hoxb5b suppresses NCC enteric expansion. Scale bar A: $100 \mu \mathrm{m}$

\section{Author Contributions}

AGA-H and RAU designed the experiments and wrote the manuscript. RAU and AGA-H conceived the idea. AGA-H, ACN, JT, PR, EWS, CL, GK and RU performed the experiments. PR and JSW created the zebrafish transgenic line. AGA-H and RAU performed the data analyses. All the authors contributed to the article and approved the submitted version.

\section{Funding}

Funding for this project was provided by Rice University, a Burroughs Wellcome Fund PDEP Award, Cancer Prevention \& Research Institute of Texas (CPRIT) Recruitment of First-Time Tenure Track Faculty Members (CPRIT-RR170062) and the NSF CAREER Award (1942019) awarded to R.A.U as well as through the NIH NHLBI (HL137766, HL141186) awarded to J.S.W.

\section{Acknowledgements}

We offer our sincerest gratitude to Dr. Dan Wagner and to the entire Uribe Lab at Rice University for their insights and support throughout this project. We thank Dr. Budi Utama and the Rice University Shared Equipment Authority on IMARIS image analysis suite, which was indispensable toward this project. We also thank Dr. Eric Bridenbaugh and Dr. Mariane Martinez at Olympus for their expert advice on confocal microscopy. 


\section{$\underline{\text { References }}$}

Barsh, G.R., Isabella, A.J., and Moens Correspondence, C.B. (2017). Vagus Motor Neuron Topographic Map Determined by Parallel Mechanisms of hox5 Expression and Time of Axon Initiation. Curr. Biol. 27, 3812-3825.

Carney, T.J., Dutton, K.A., Greenhill, E., Delfino-Machin, M., Dufourcq, P., Blader, P., and Kelsh, R.N. (2006). A direct role for Sox10 in specification of neural crest-derived sensory neurons. Development 113, 4619-4630.

Choi, H.M.T., Chang, J.Y., Trinh, L.A., Padilla, J.E., Fraser, S.E., and Pierce, N.A. (2010). Programmable in situ amplification for multiplexed imaging of mRNA expression. Nat.

Biotechnol. 28, 1208-1212.

Choi, H.M.T., Calvert, C.R., Husain, N., Huss, D., Barsi, J.C., Deverman, B.E., Hunter, R.C., Kato, M., Lee, S.M., Abelin, A.C.T., et al. (2016). Mapping a multiplexed zoo of mRNA expression. Development 143, 3632-3637.

Choi, H.M.T., Schwarzkopf, M., Fornace, M.E., Acharya, A., Artavanis, G., Stegmaier, J., Cunha, A., and Pierce, N.A. (2018). Third-generation in situ hybridization chain reaction: multiplexed, quantitative, sensitive, versatile, robust. Development 145, dev165753.

Dalgin, G., and Prince, V.E. (2021). Midline morphogenesis of zebrafish foregut endoderm is dependent on Hoxb5b. Dev. Biol. 471, 1-9.

Le Douarin, N.M. (1982). The Neural Crest (Cambridge: Cambridge University Press).

Le Douarin, N., and Kalcheim, C. (1999). The Neural Crest (Cambridge University Press).

Durbec, P.L., Larsson-blomberg, L.B., Schuchardt, A., Costantini, F., and Pachnis, V. (1996). Common origin and developmental dependence on c-ret of subsets of enteric and sympathetic neuroblasts. Development 122, 349-358. 
Elworthy, S., Pinto, J.P., Pettifer, A., Cancela, M.L., and Kelsh, R.N. (2005). Phox2b function in the enteric nervous system is conserved in zebrafish and is sox10-dependent. Mech. Dev. 122, 659-669.

Ganz, J. (2018). Gut feelings: Studying enteric nervous system development, function, and disease in the zebrafish model system. Dev. Dyn. 247, 268-278.

Harrison, C., Wabbersen, T., and Shepherd, I. (2014). In Vivo Visualization of the Development of the Enteric Nervous System Using a Tg(-8.3bphox2b:Kaede) Transgenic Zebrafish. Genesis 52, 985-990.

Hochgreb-Hagele, T., and Bronner, M.E. (2013). A novel FoxD3 gene trap line reveals neural crest precursor movement and a role for FoxD3 in their specification. Dev. Biol. 374, 1-11.

Hortopan, G.A., and Baraban, S.C. (2011). Aberrant expression of genes necessary for neuronal development and notch signaling in an epileptic mind bomb zebrafish. Dev. Dyn. 240, 1964-1976.

Howard, A.G.A., Baker, P.A., Ibarra-García-Padilla, R., Moore, J.A., Rivas, L.J., Tallman, J.J., Singleton, E.W., Westheimer, J.L., Corteguera, J.A., and Uribe, R.A. (2021). An atlas of neural crest lineages along the posterior developing zebrafish at single-cell resolution. Elife 10, e60005.

Howe, D.G., Bradford, Y.M., Conlin, T., Eagle, A.E., Fashena, D., Frazer, K., Knight, J., Mani, P., Martin, R., Moxon, S.A.T., et al. (2013). ZFIN, the Zebrafish Model Organism Database: increased support for mutants and transgenics. Nucleic Acids Res. 41, D854-60.

Hutchins, E.J., Kunttas, E., Piacentino, M.L., Howard, A.G.A., Bronner, M.E., and Uribe, R.A. (2018). Migration and Diversification of the Vagal Neural Crest. Dev. Biol. 18, 30214-30269.

Ibarra-García-Padilla, R., Howard, A.G.A., Singleton, E.W., and Uribe, R.A. (2021). A protocol for whole-mount immuno-coupled hybridization chain reaction (WICHCR) in zebrafish embryos 
and larvae. STAR Protoc. 2, 100709.

Jarinova, O., Hatch, G., Poitras, L., Prudhomme, C., Grzyb, M., Aubin, J., Bérubé-Simard, F.-A., Jeannotte, L., and Ekker, M. (2008). Functional resolution of duplicated hoxb5 genes in teleosts. Development 135, 3543-3553.

Jowett, T., and Lettice, L. (1994). Whole-mount in situ hybridizations on zebrafish embryos using a mixture of digoxigenin- and fluorescein- labelled probes. Trends Genet. 10, 73-74.

Kam, M.K.M.M., and Lui, V.C.H.H. (2015). Roles of Hoxb5 in the development of vagal and trunk neural crest cells. Dev. Growth Differ. 57, 158-168.

Kam, M.K.M., Cheung, M., Zhu, J.J., Cheng, W.W.C., Sat, E.W.Y., Tam, P.K.H., and Lui, V.C.H. (2014a). Homeobox b5 (Hoxb5) regulates the expression of Forkhead box D3 gene (Foxd3) in neural crest. Int. J. Biochem. Cell Biol. 55, 144-152.

Kam, M.K.M., Cheung, M.C.H., Zhu, J.J., Cheng, W.W.C., Sat, E.W.Y., Tam, P.K.H., and Lui, V.C.H. (2014b). Perturbation of Hoxb5 signaling in vagal and trunk neural crest cells causes apoptosis and neurocristopathies in mice. Cell Death Differ. 21, 278-289.

Karlsson, J., Von Hofsten, J., and Olsson, P.E. (2001). Generating transparent zebrafish: A refined method to improve detection of gene expression during embryonic development. Mar. Biotechnol. 3, 522-527.

Kawakami, K. (2004). Transgenesis and gene trap methods in zebrafish by using the Tol2 transposable element. In Methods in Cell Biology, (Academic Press Inc.), pp. 201-222.

Kawakami, K., Takeda, H., Kawakami, N., Kobayashi, M., Matsuda, N., and Mishina, M. (2004). A transposon-mediated gene trap approach identifies developmentally regulated genes in zebrafish. Dev. Cell 7, 133-144.

Kucenas, S., Takada, N., Park, H.C., Woodruff, E., Broadie, K., and Appel, B. (2008). CNS- 
derived glia ensheath peripheral nerves and mediate motor root development. Nat. Neurosci.

$11,143-151$.

Kudoh, T., Tsang, M., Hukriede, N.A., Chen, X., Dedekian, M., Clarke, C.J., Kiang, A., Schultz,

S., Epstein, J.A., Toyama, R., et al. (2001). A gene expression screen in zebrafish

embryogenesis. Genome Res. 11, 1979-1987.

Kwan, K.M., Fujimoto, E., Grabher, C., Mangum, B.D., Hardy, M.E., Campbell, D.S., Parant, J.M., Yost, H.J., Kanki, J.P., and Chien, C.-B. (2007). The Tol2kit: A multisite gateway-based construction kit forTol2 transposon transgenesis constructs. Dev. Dyn. 236, 3088-3099.

Lengerke, C., Schmitt, S., Bowman, T. V., Jang, I.H., Maouche-Chretien, L., McKinney-

Freeman, S., Davidson, A.J., Hammerschmidt, M., Rentzsch, F., Green, J.B.A., et al. (2008).

BMP and Wnt Specify Hematopoietic Fate by Activation of the Cdx-Hox Pathway. Cell Stem

Cell 2, 72-82.

Lister, J.A., Cooper, C., Nguyen, K., Modrell, M., Grant, K., and Raible, D.W. (2006). Zebrafish Foxd3 is required for development of a subset of neural crest derivatives. Dev. Biol. 290, 92104.

Lui, V.C.H.H., Cheng, W.W.C., Leon, T.Y.Y., Lau, D.K.C., Garcia-Barcelo, M.-M., Miao, X.P., Kam, M.K.M., So, M.T., Chen, Y., Wall, N.A., et al. (2008). Perturbation of Hoxb5 Signaling in Vagal Neural Crests Down-Regulates Ret Leading to Intestinal Hypoganglionosis in Mice.

Gastroenterology 134, 1104-1115.

Lukoseviciute, M., Gavriouchkina, D., Williams, R.M., Hochgreb-Hagele, T., Senanayake, U., Chong-Morrison, V., Thongjuea, S., Repapi, E., Mead, A., and Sauka-Spengler, T. (2018). From Pioneer to Repressor: Bimodal foxd3 Activity Dynamically Remodels Neural Crest Regulatory Landscape In Vivo. Dev. Cell 47, 608-628.

Luo, R., An, M., Arduini, B.L., and Henion, P.D. (2001). Specific pan-neural crest expression of 
zebrafish Crestin throughout embryonic development. Dev. Dyn. 220, 169-174.

Mandal, A., Rydeen, A., Anderson, J., Sorrell, M.R.J., Zygmunt, T., Torres-Vázquez, J., and Waxman, J.S. (2013). Transgenic retinoic acid sensor lines in zebrafish indicate regions of available embryonic retinoic acid. Dev. Dyn. 242, 989-1000.

Martik, M.L., and Bronner, M.E. (2017). Regulatory Logic Underlying Diversification of the Neural Crest. Trends Genet. 33, 715-727.

Odenthal, J., and Nüsslein-Volhard, C. (1998). fork head domain genes in zebrafish. Dev. Genes, Evoloution 208, 245-258.

Parker, H.J., De Kumar, B., Green, S.A., Prummel, K.D., Hess, C., Kaufman, C.K., Mosimann, C., Wiedemann, L.M., Bronner, M.E., and Krumlauf, R. (2019). A Hox-TALE regulatory circuit for neural crest patterning is conserved across vertebrates. Nat. Commun. 10, 1182.

Pattyn, A., Morin, X., Cremer, H., Goridis, C., and Brunet, J.-F. (1999). The homeobox gene Phox $2 b$ is essential for the development of autonomic neural crest derivatives. Nature 399, 366-370.

Petratou, K., Spencer, S.A., Kelsh, R.N., and Lister, J.A. (2021). The MITF paralog tfec is required in neural crest development for fate specification of the iridophore lineage from a multipotent pigment cell progenitor. PLoS One 16, e0244794.

Rocha, M., Singh, N., Ahsan, J., Beiriger, A., and Prince, V.E. (2020). Neural crest development: Insights from the zebrafish. Dev. Dyn. 249, 88-111.

Rueden, C.T., Schindelin, J., Hiner, M.C., Dezonia, B.E., Walter, A.E., Arena, E.T., and Eliceiri, K.W. (2017). ImageJ2: ImageJ for the next generation of scientific image data. BMC Bioinformatics 18, 529 .

Ruzicka, L., Howe, D.G., Ramachandran, S., Toro, S., Van Slyke, C.E., Bradford, Y.M., Eagle, 
A., Fashena, D., Frazer, K., Kalita, P., et al. (2019). The Zebrafish Information Network: new support for non-coding genes, richer Gene Ontology annotations and the Alliance of Genome Resources. Nucleic Acids Res. 47, D867-873.

Schindelin, J., Arganda-Carreras, I., Frise, E., Kaynig, V., Longair, M., Pietzsch, T., Preibisch, S., Rueden, C., Saalfeld, S., Schmid, B., et al. (2012). Fiji: an open-source platform for biological-image analysis. Nat. Methods 9, 676-682.

Schneider, C.A., Rasband, W.S., and Eliceiri, K.W. (2012). NIH Image to ImageJ: 25 years of image analysis. Nat. Methods 9, 671-675.

Simoes-Costa, M., and Bronner, M.E. (2016). Reprogramming of avian neural crest axial identity and cell fate. Science 352, 1570-1573.

Soldatov, R., Kaucka, M., Kastriti, M.E., Petersen, J., Chontorotzea, T., Englmaier, L., Akkuratova, N., Yang, Y., Häring, M., Dyachuk, V., et al. (2019). Spatio-temporal structure of cell fate decisions in murine neural crest. Science 364, eaas9536.

Sorrells, S., Toruno, C., Stewart, R.A., and Jette, C. (2013). Analysis of Apoptosis in Zebrafish Embryos by Whole-mount Immunofluorescence to Detect Activated Caspase 3. J. Vis. Exp 82, 51060.

Tang, W., Li, Y., Li, A., and Bronner, M.E. (2021). Clonal analysis and dynamic imaging identify multipotency of individual Gallus gallus caudal hindbrain neural crest cells toward cardiac and enteric fates. Nat. Commun. 12, 1894.

Tennyson, V.M., Gershon, M.D., Sherman, D.L., Behringer, R.R., Raz, R., Crotty, D.A., and Wolgemuth, D.J. (1993). Structural Abnormalities Associated With Congenital Megacolon in Transgenic Mice That Overexpress the Hoxa-4 Gene. Dev. Dyn. 198, 28-53.

Uribe, R.A., and Bronner, M.E. (2015). Meis3 is required for neural crest invasion of the gut during zebrafish enteric nervous system development. Mol. Biol. Cell 26, 3728-3740. 
van der Velden, Y.U., Wang, L., van Lohuizen, M., and Haramis, A.-P.G. (2012). The Polycomb group protein Ring1b is essential for pectoral fin development. Development 139, 2210-2220.

Waxman, J.S., and Yelon, D. (2009). Increased hox activity mimics the teratogenic effects of excess retinoic acid signaling. Dev. Dyn. 238, 1207-1213.

Waxman, J.S., Keegan, B.R., Roberts, R.W., Poss, K.D., and Yelon, D. (2008). Hoxb5b Acts Downstream of Retinoic Acid Signaling in the Forelimb Field to Restrict Heart Field Potential in Zebrafish. Dev. Cell 15, 923-934.

Wolgemuth, D.J., Behringer, R.R., Mostoller, M.P., Brinster, R.L., and Palmiter, R.D. (1989). Transgenic mice overexpressing the mouse homeobox-containing gene Hox-1.4 exhibit abnormal gut development. Nature 337, 464-467. 
bioRxiv preprint doi: https://doi.org/10.1101/2021.10.28.466356; this version posted October 29,2021 . The copyright holder for this preprint (which was not certified by peer review) is the author/funder, who has granted bioRxiv a license to display the preprint in perpetuity. It is made available under aCC-BY-NC-ND 4.0 International license.

Figure 1
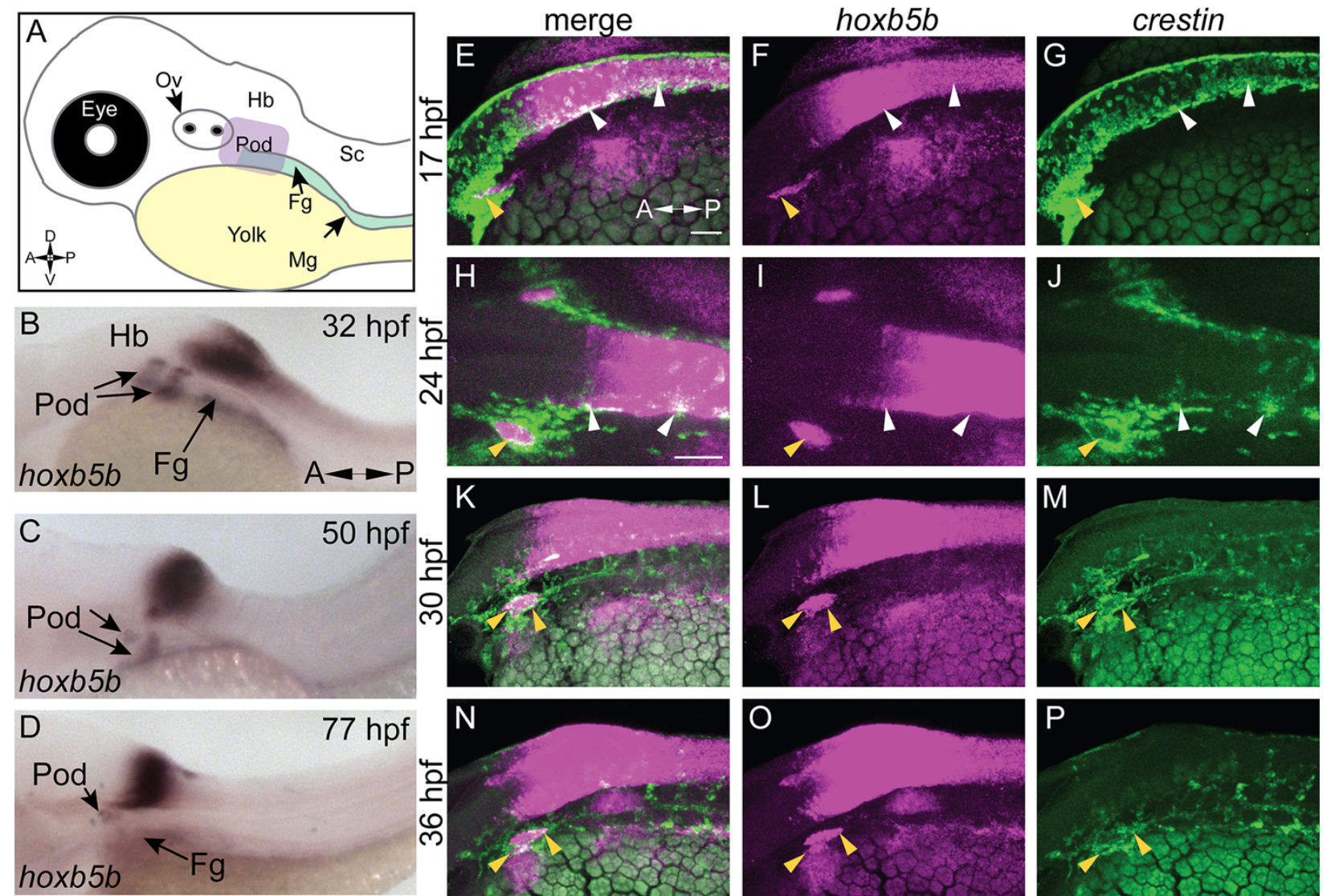

$77 \mathrm{hpf}$
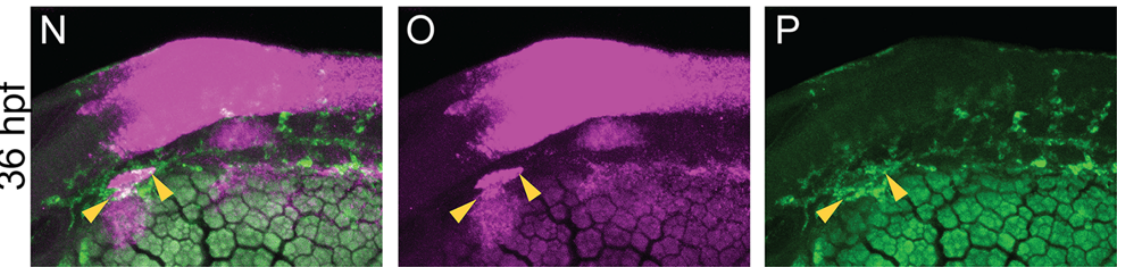
Figure 2

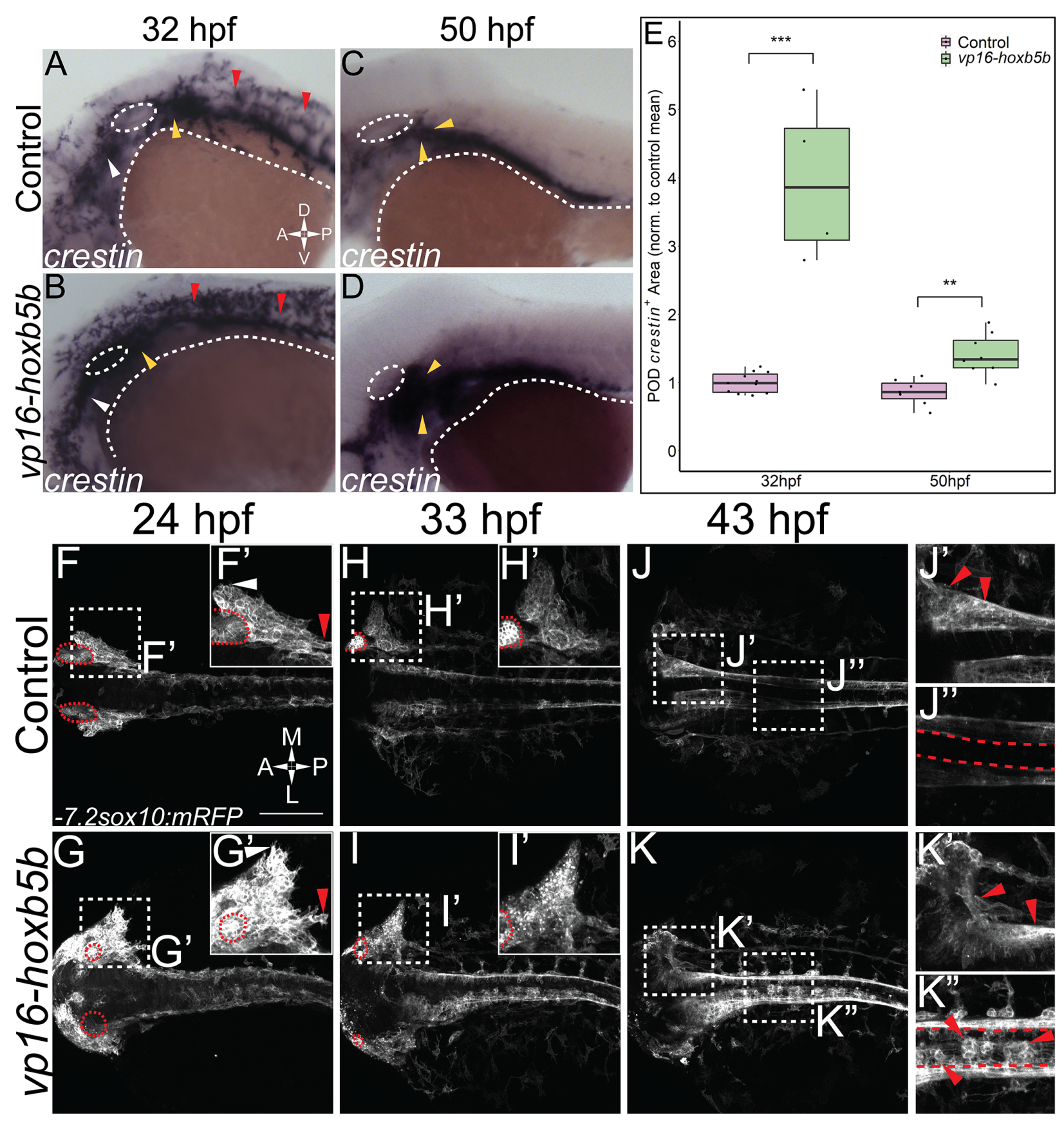


bioRxiv preprint doi: https://doi.org/10.1101/2021.10.28.466356; this version posted October 29,2021 . The copyright holder for this preprint (which was not certified by peer review) is the author/funder, who has granted bioRxiv a license to display the preprint in perpetuity. It is made available under aCC-BY-NC-ND 4.0 International license.

Figure 3
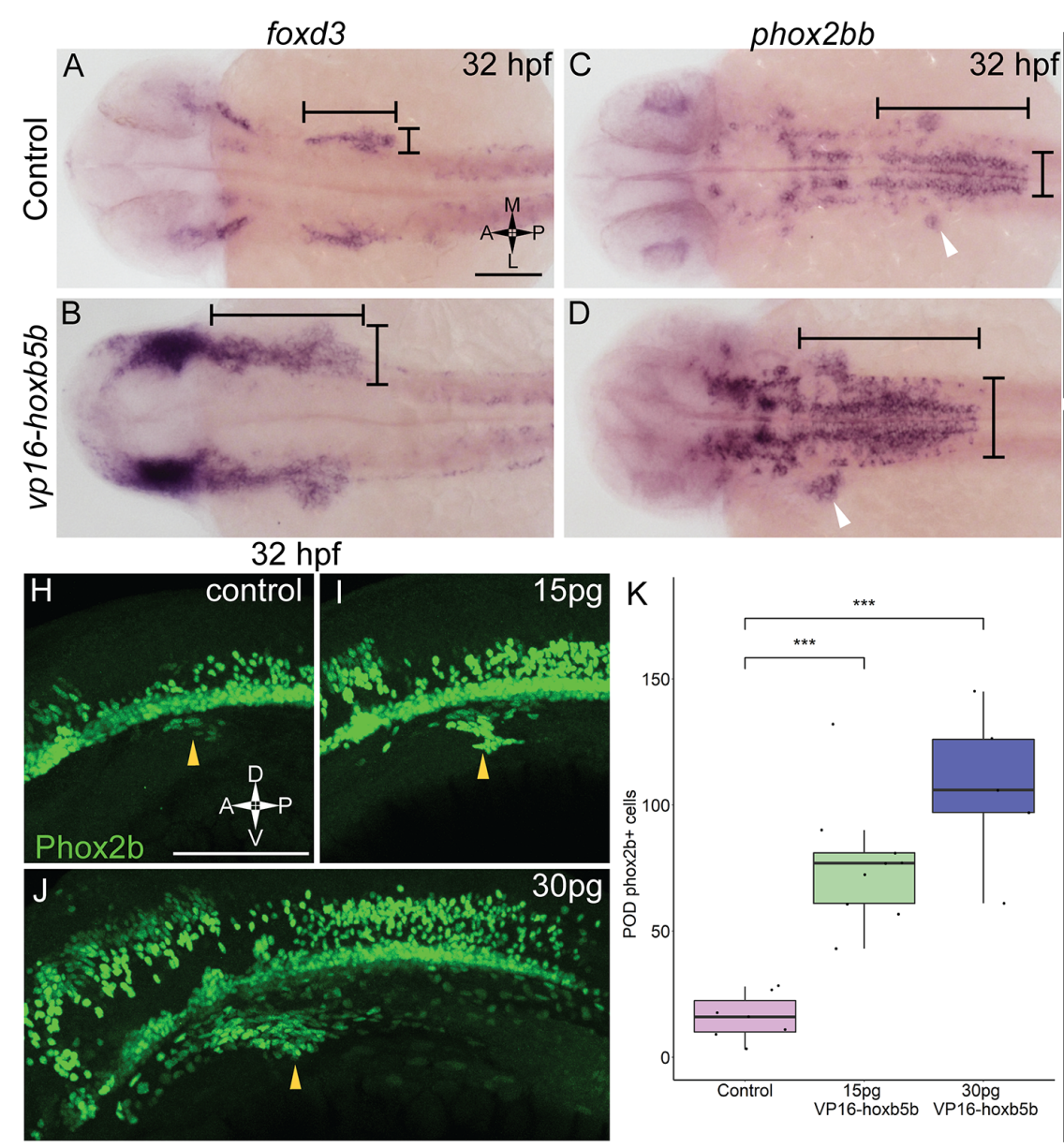

phox $2 b b$
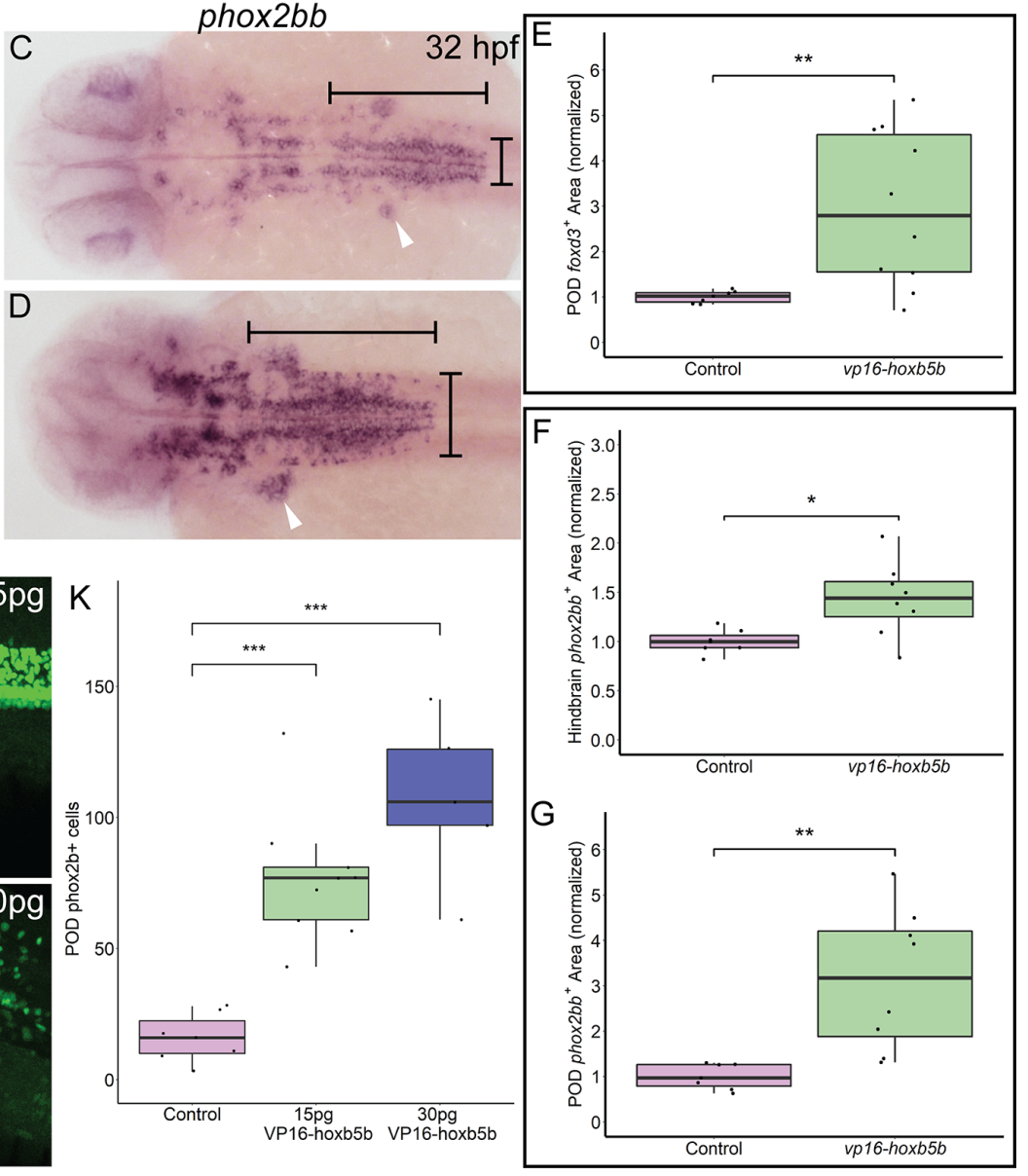
Figure 4
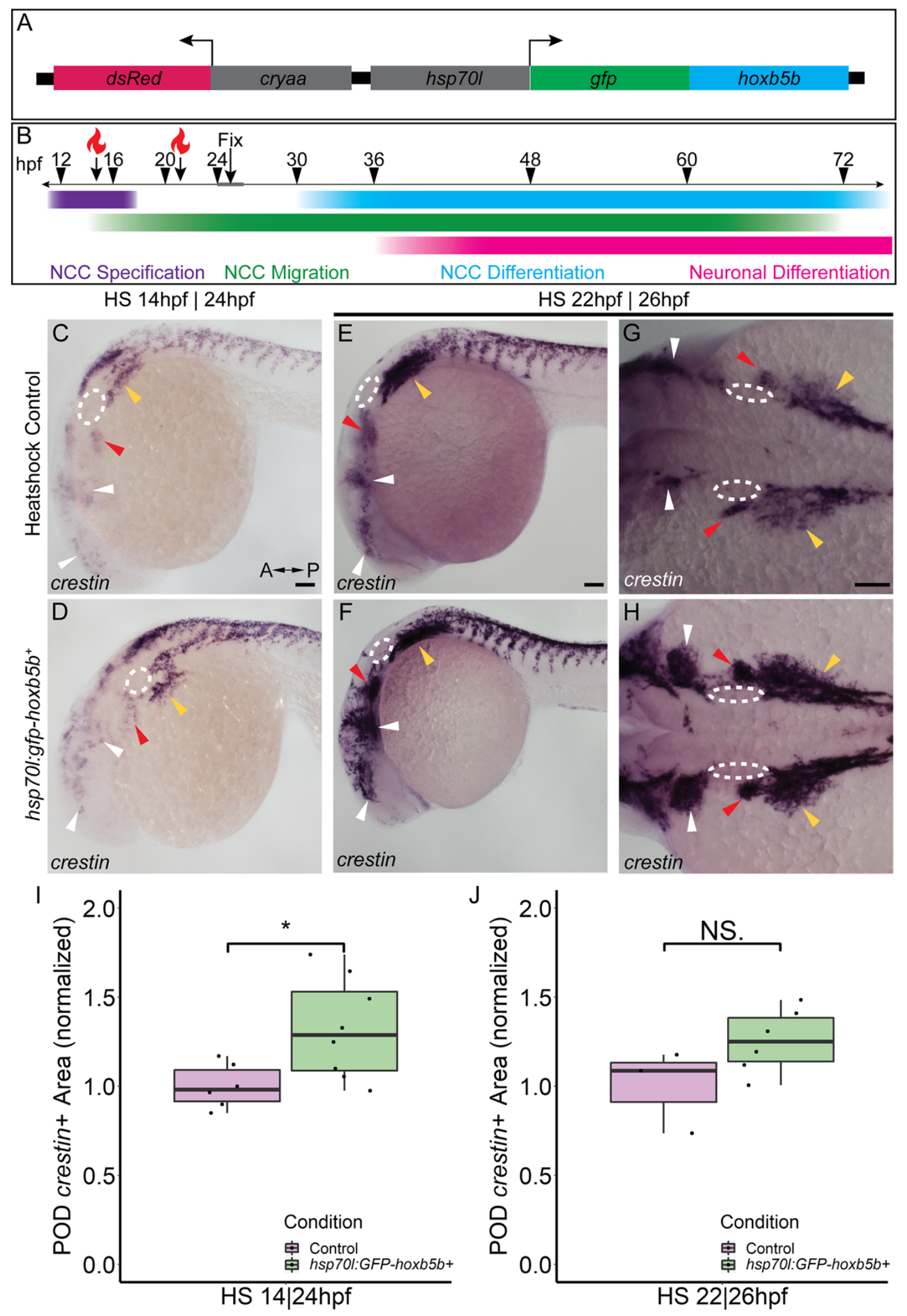
bioRxiv preprint doi: https://doi.org/10.1101/2021.10.28.466356; this version posted October 29, 2021. The copyright holder for this preprint (which was not certified by peer review) is the author/funder, who has granted bioRxiv a license to display the preprint in perpetuity. It is made available under aCC-BY-NC-ND 4.0 International license.

\section{Figure 5}

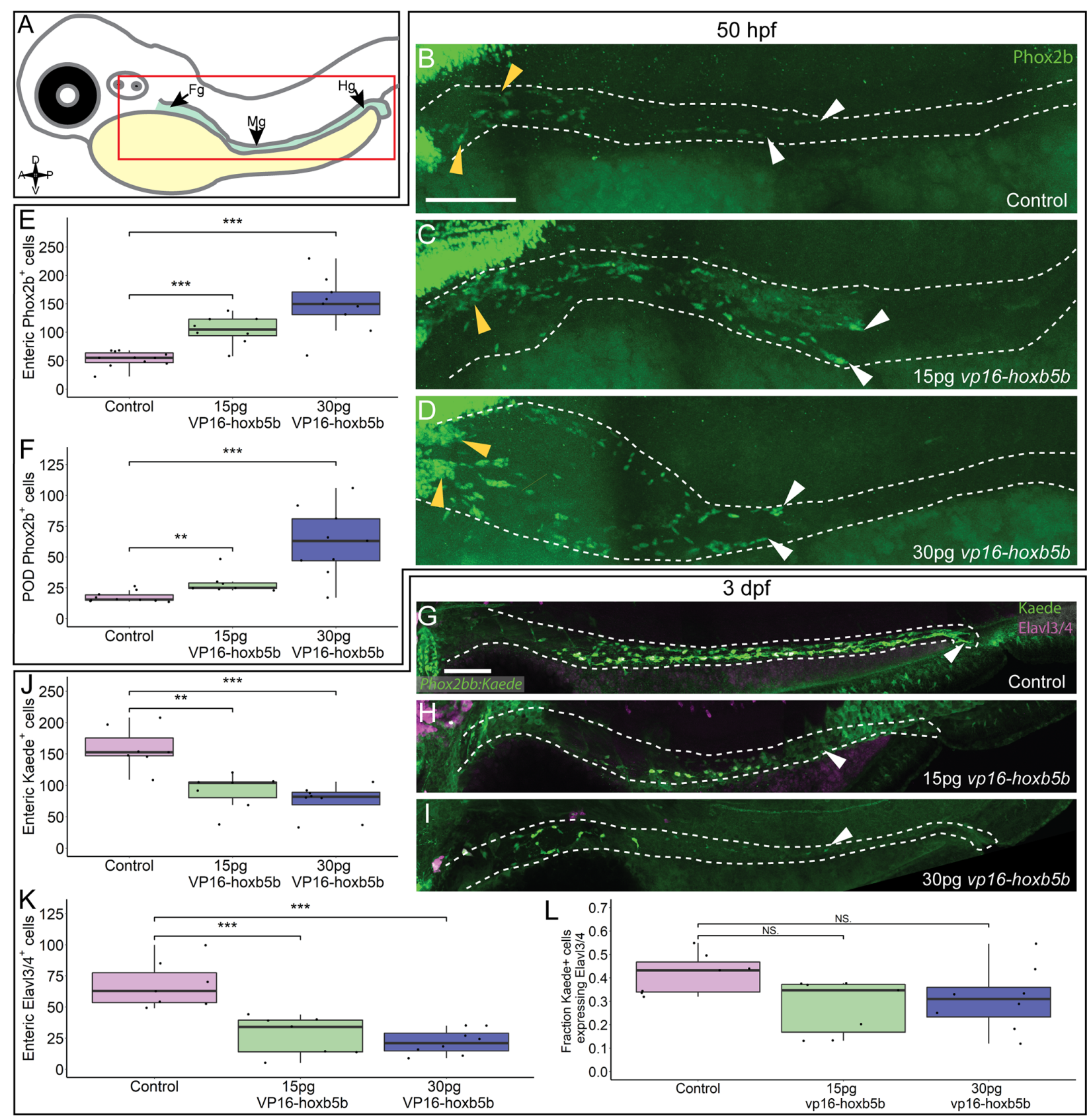


bioRxiv preprint doi: https://doi.org/10.1101/2021.10.28.466356; this version posted October 29, 2021. The copyright holder for this preprint (which was not certified by peer review) is the author/funder, who has granted bioRxiv a license to display the preprint in perpetuity. It is made available under aCC-BY-NC-ND 4.0 International license.

Figure 6
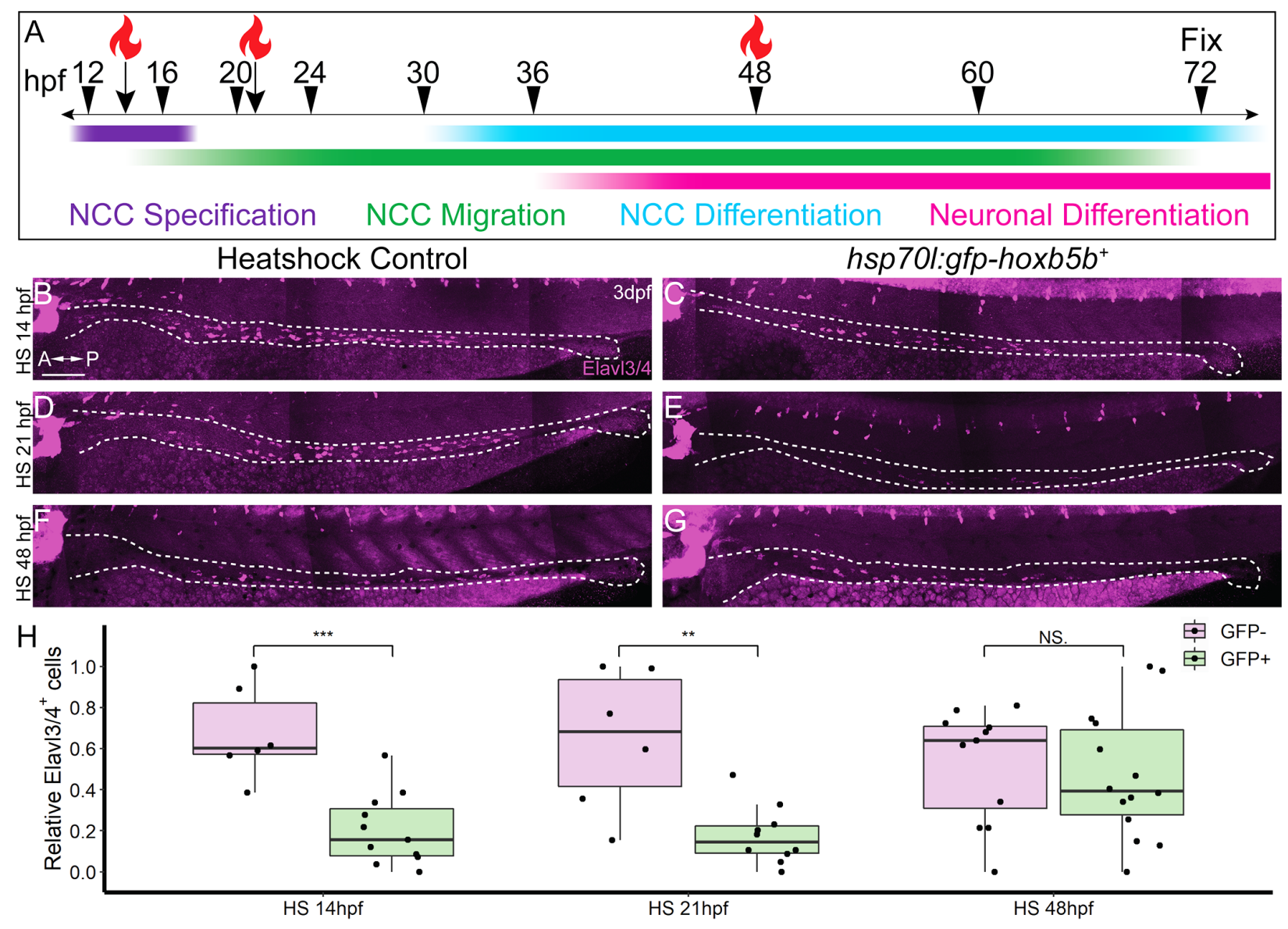
bioRxiv preprint doi: https://doi.org/10.1101/2021.1028.466356; this version posted October 29,2021 . The copyright holder for this preprint (which was not certified by peer review) is the author/funder, who has granted bioRxiv a license to display the preprint in perpetuity. It is made available under aCC-BY-NC-ND 4.0 International license.

\section{Figure 7}
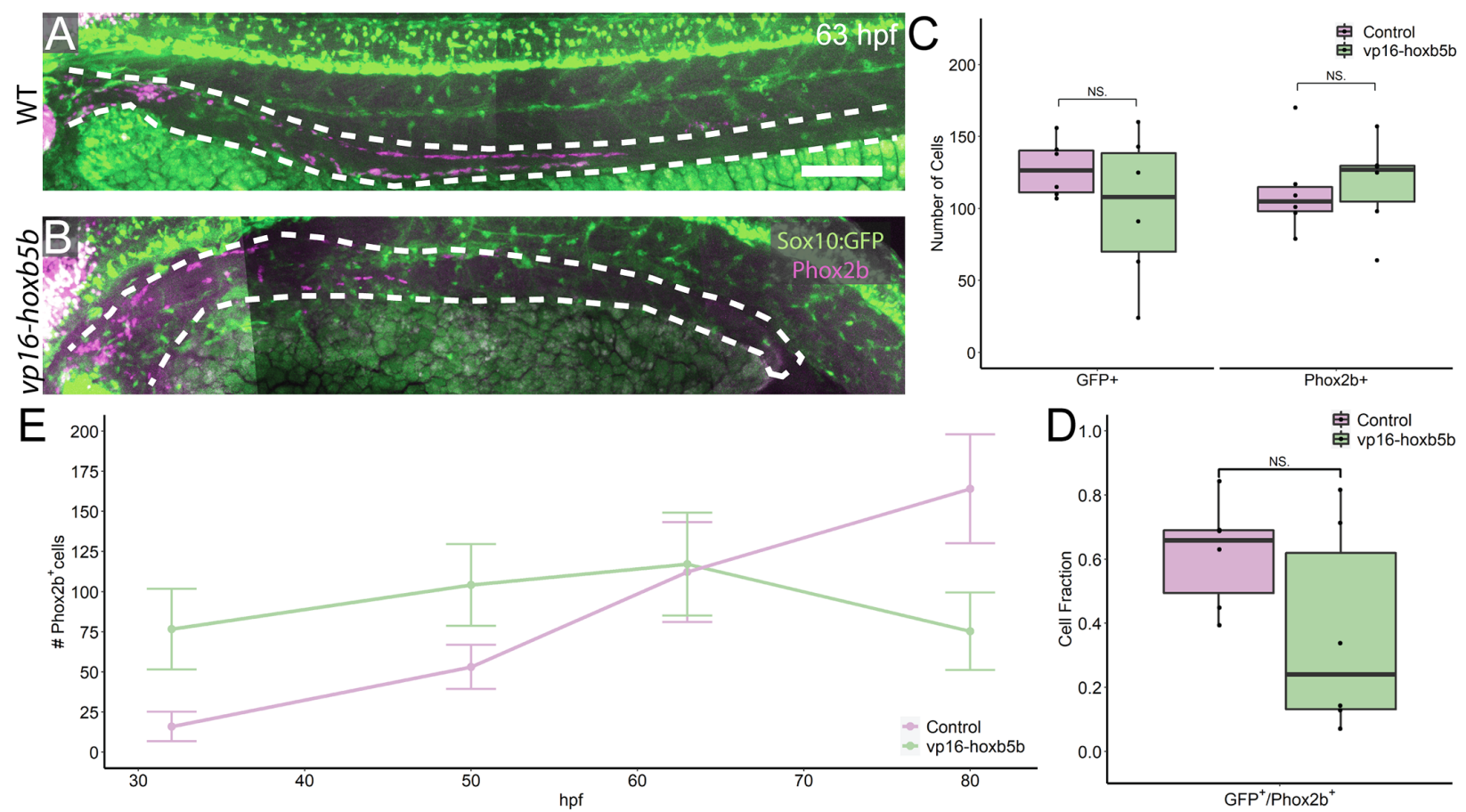

$\mathrm{F}$
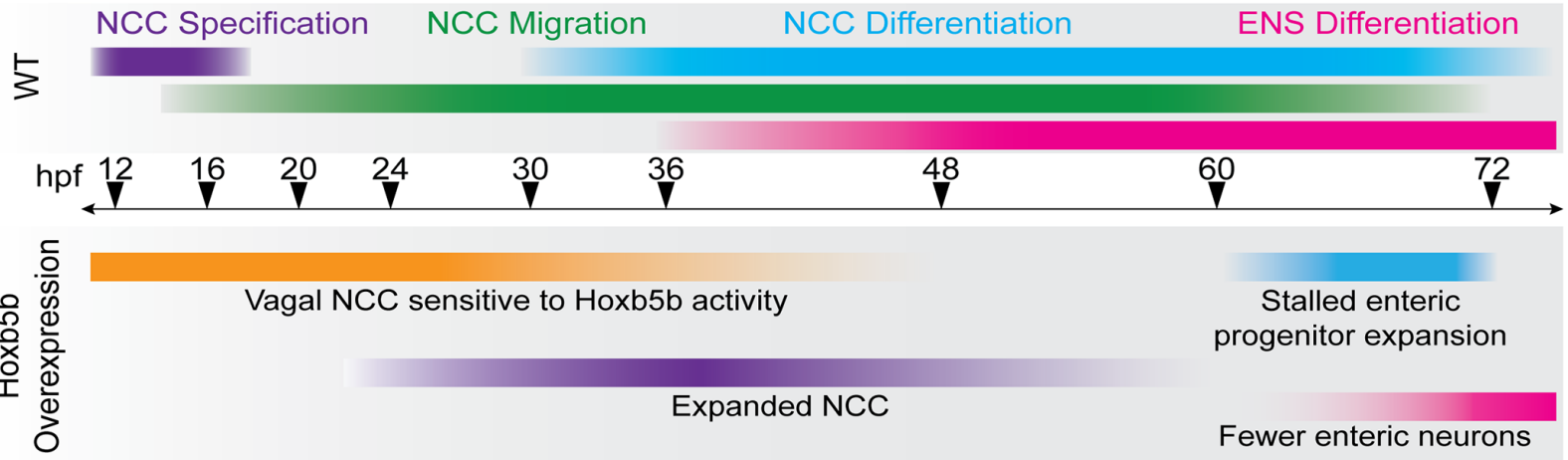
bioRxiv preprint doi: https://doi.org/10.1101/2021.10.28.466356; this version posted October 29, 2021. The copyright holder for this preprint (which was not certified by peer review) is the author/funder, who has granted bioRxiv a license to display the preprint in perpetuity. It is made available under aCC-BY-NC-ND 4.0 International license.

\section{Figure 3 Supplement 1}

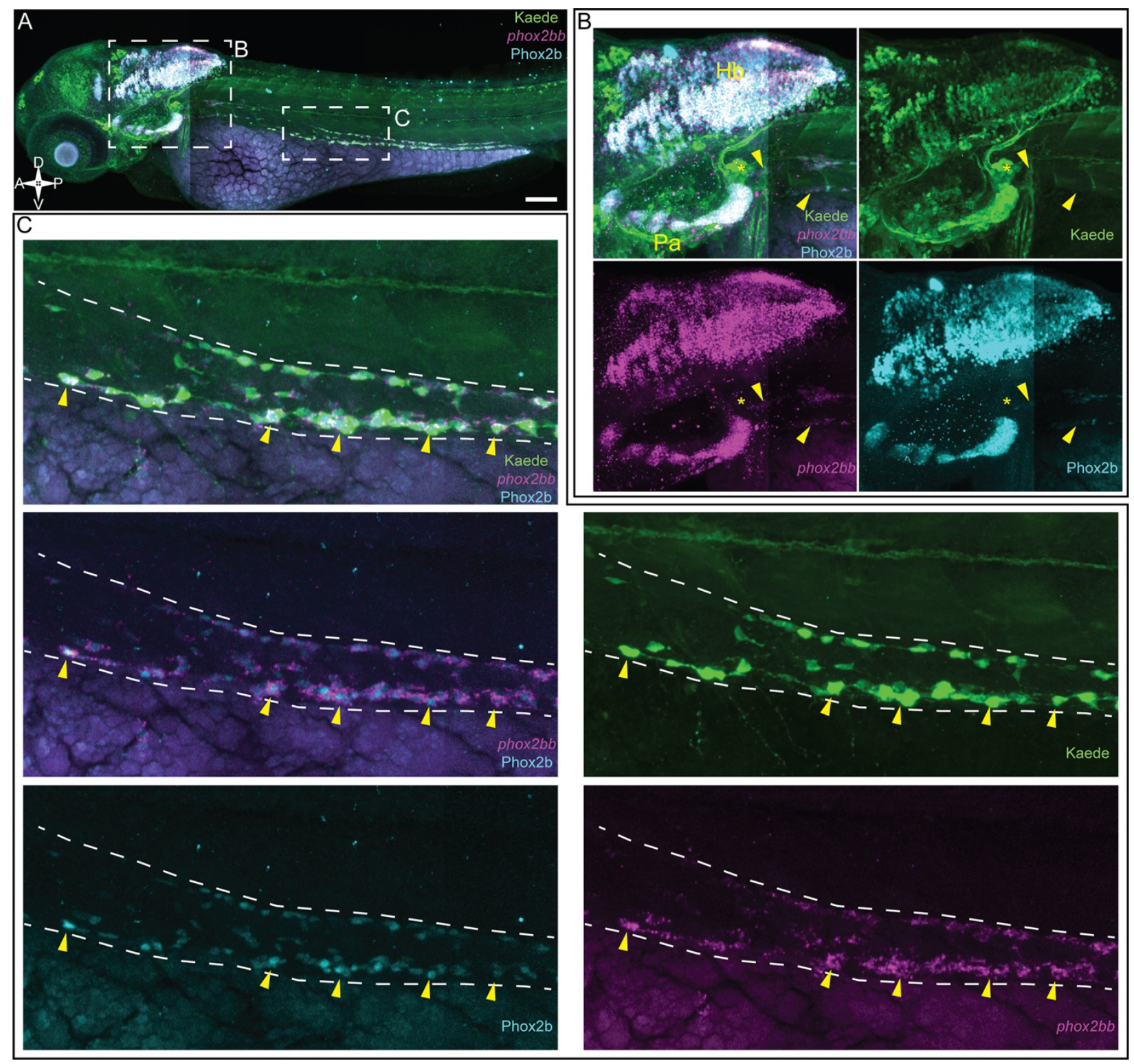


bioRxiv preprint doi: https://doi.org/10.1101/2021.10.28.466356; this version posted October 29, 2021. The copyright holder for this preprint (which was not certified by peer review) is the author/funder, who has granted bioRxiv a license to display the preprint in perpetuity. It is made available under aCC-BY-NC-ND 4.0 International license.

\section{Figure 4 Supplement 1}

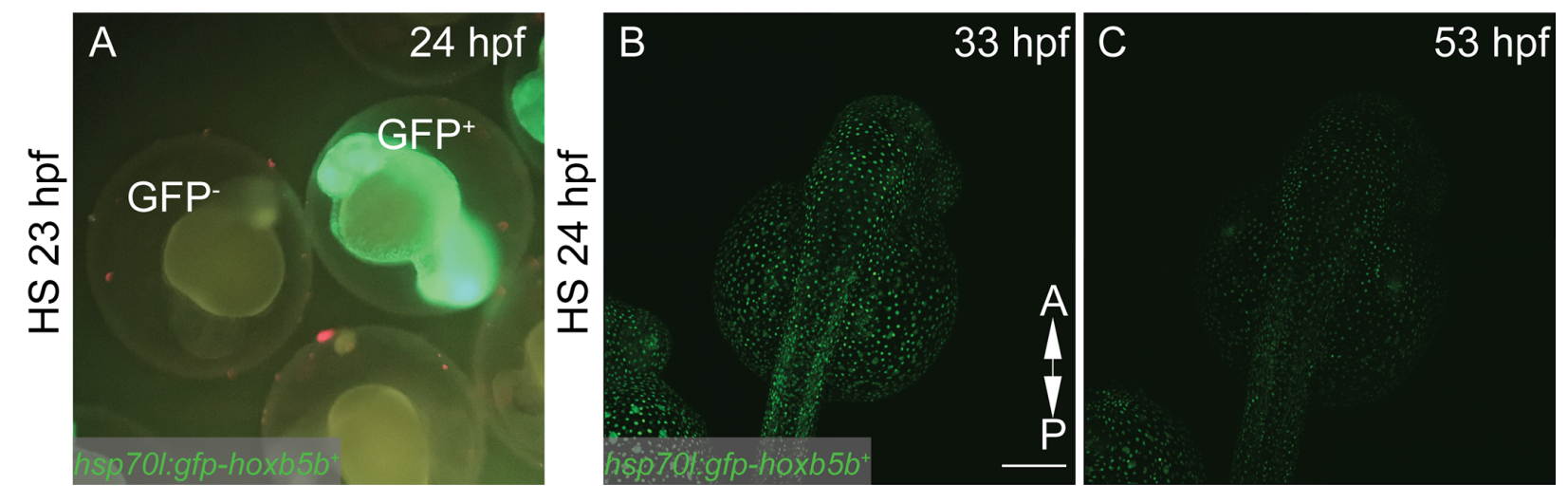


bioRxiv preprint doi: https://doi.org/10.1101/2021.10.28.466356; this version posted October 29, 2021. The copyright holder for this preprint (which was not certified by peer review) is the author/funder, who has granted bioRxiv a license to display the preprint in perpetuity. It is made available under aCC-BY-NC-ND 4.0 International license.

Figure 5 Supplement 1
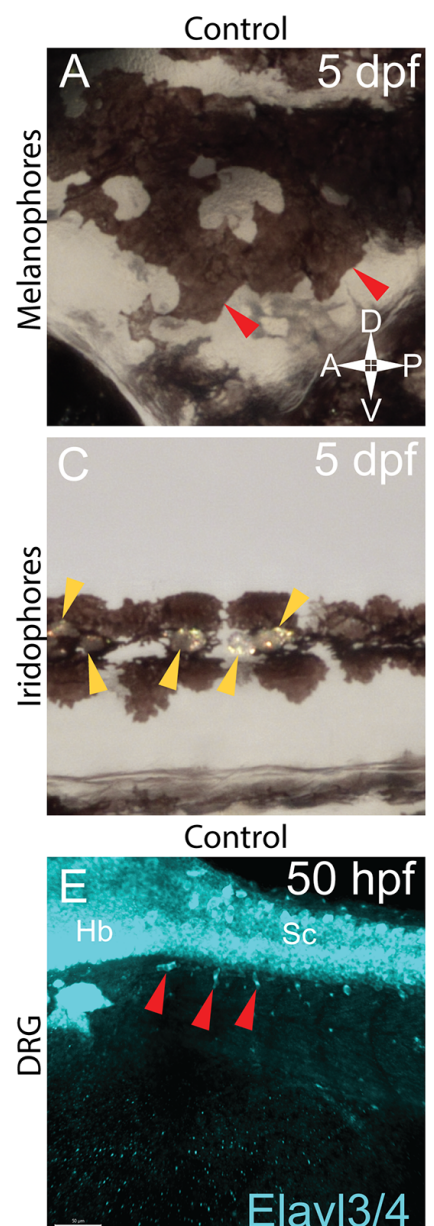

vp16-hoxb5b
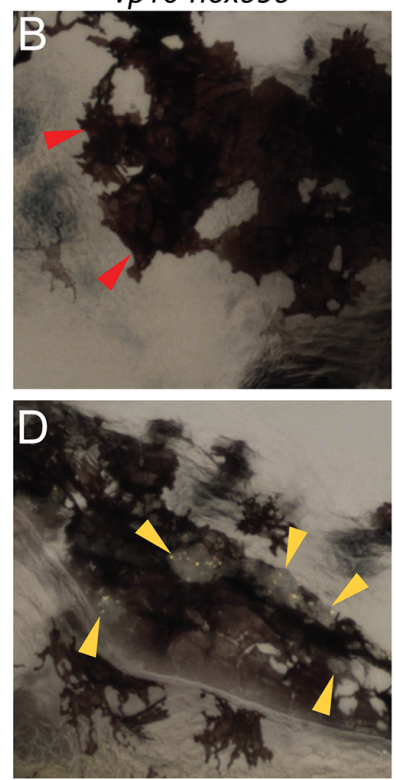

vp16-hoxb5b

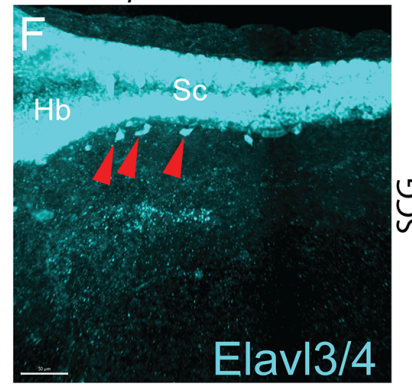

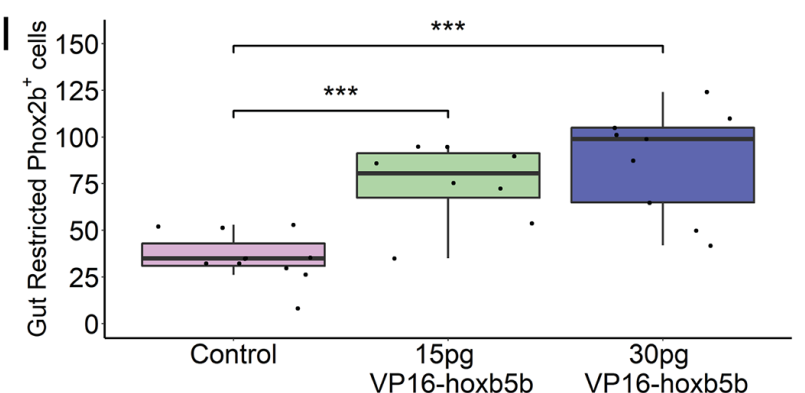

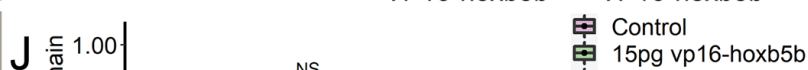

审 $30 \mathrm{pg}$ vp16-hoxb5b

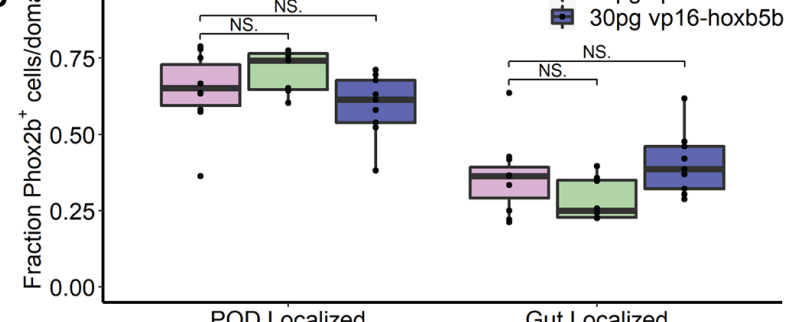

\section{Control}

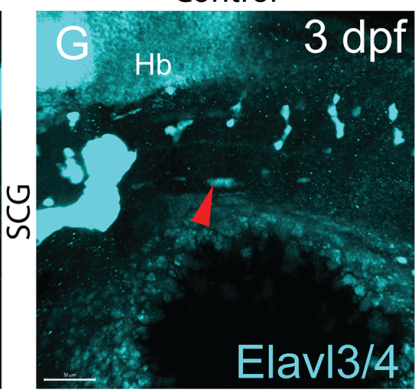

Gut Localized

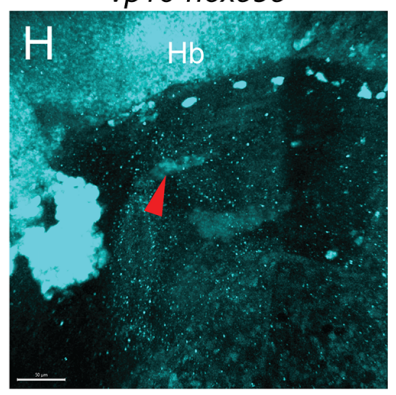


bioRxiv preprint doi: https://doi.org/10.1101/2021.10.28.466356; this version posted October 29, 2021. The copyright holder for this preprint (which was not certified by peer review) is the author/funder, who has granted bioRxiv a license to display the preprint in perpetuity. It is made available under aCC-BY-NC-ND 4.0 International license.

\section{Figure 7 Supplement 1}
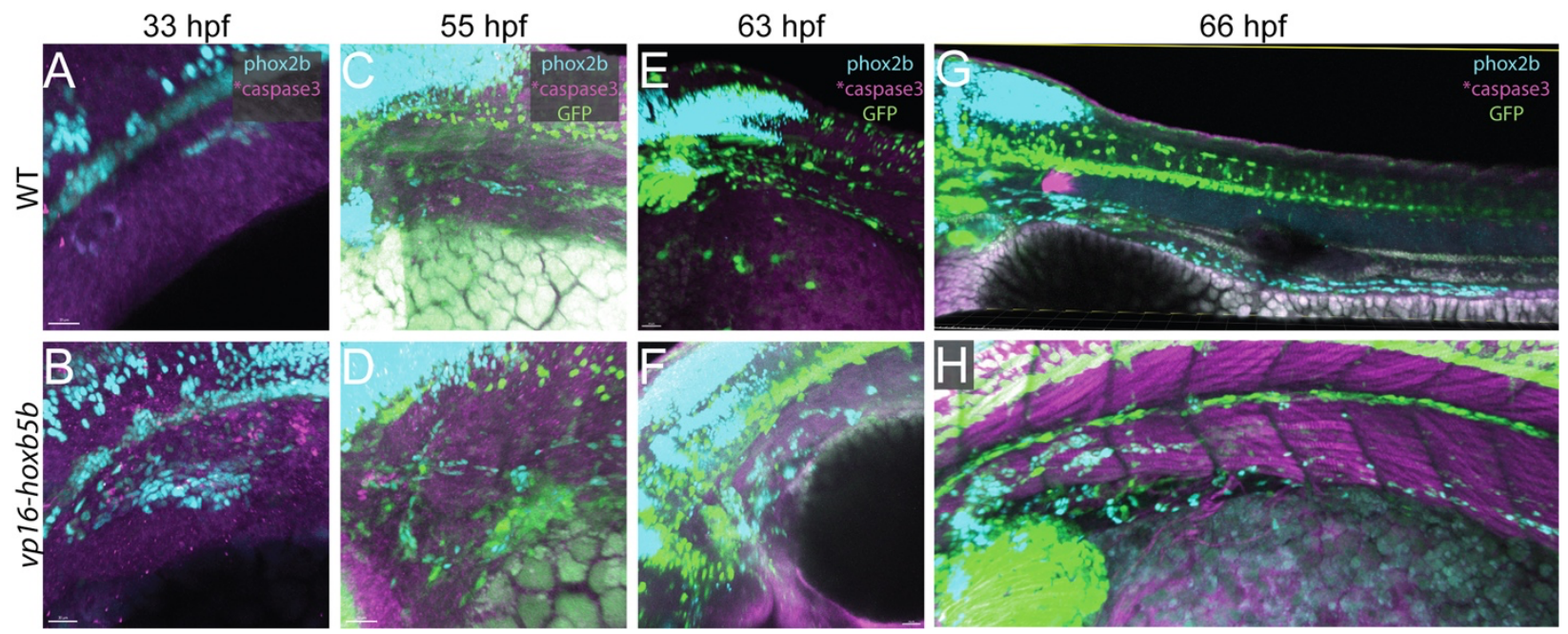